\title{
Human blood DNA methylation patterns reflect individual lifestyle
} Rohde-Zimmermann ${ }^{1,2}$, Anke Tönjes ${ }^{1}$, Joachim Thiery ${ }^{4}$, Markus Löffler ${ }^{3}$, Ralph Burkhardt ${ }^{5}$, Yvonne Böttcher ${ }^{6,7}$, Michael Stumvoll ${ }^{1,2,8}$, Matthias Blüher ${ }^{1,2}$, Knut Krohn ${ }^{9}$, Markus Scholz ${ }^{3,10}$, Ronny Baber ${ }^{9,10}$, Paul W Franks ${ }^{11}$, Peter Kovacs, ${ }^{1 \#}$, Maria Keller ${ }^{1,2, \#}$

1 Medical Department III - Endocrinology, Nephrology, Rheumatology, University of Leipzig Medical Center, Leipzig 04103, Germany

2 Helmholtz Institute for Metabolic, Obesity and Vascular Research (HI-MAG) of the Helmholtz Center Munich at the University of Leipzig and University Hospital Leipzig, Leipzig, 04103, Germany

3 Institute for Medical Informatics, Statistics and Epidemiology, University of Leipzig, 04103 Leipzig, Germany

$4 \quad$ Medical Faculty, University of Kiel, 24118 Kiel, Germany

5 Institute of Clinical Chemistry and Laboratory Medicine, University Hospital Regensburg, 93053 Regensburg, Germany

6 Department of Clinical Molecular Biology, Institute of Clinical Medicine, University of Oslo, 0316 Oslo, Norway

7 Medical Division, Akershus University Hospital, 1478 Lørenskog, Norway

8 Deutsches Zentrum für Diabetesforschung, 85764 Neuherberg, Germany

9 Medical Faculty, University of Leipzig, 04103 Leipzig, Germany

10 LIFE Leipzig Research Center for Civilization Diseases, University of Leipzig, 04103 Leipzig, Germany

11 Genetic and Molecular Epidemiology Unit, Department of Clinical Sciences, Lund University, Skåne University Hospital, 21428 Malmö, Sweden

*Authors contributed equally

\#corresponding authors:

Maria Keller, $\mathrm{PhD}$

Helmholtz Institute for Metabolic, Obesity and Vascular Research (HI-MAG) of the Helmholtz Center Munich at the University of Leipzig and University Hospital Leipzig, Leipzig, 04103, Germany

Tel: +49 34199722932; Fax: +49 3419715949

E-Mail: maria.keller@helmholtz-muenchen.de

Peter Kovacs, $\mathrm{PhD}$;

Medical Department III - Endocrinology, Nephrology, Rheumatology, University of Leipzig

Medical Center, University of Leipzig, Liebigstrasse 21, 04103, Leipzig, Germany

Tel: 0049341 9715892; Fax: 00493419715979

E-mail: peter.kovacs@medizin.uni-leipzig.de

\section{Word count: 3964}




\section{Abstract}

44 Obesity is driven by modifiable lifestyle factors whose effects may be mediated by epigenetics.

45 Therefore, we investigated lifestyle effects (diet, physical activity, smoking and alcohol) on blood

46 DNA methylation in participants of the LIFE-Adult study, a well-characterized population-based

47 cohort from Germany. Fifty subjects with an extremely healthy and 50 with an extremely

48 unhealthy lifestyle were selected for genome-wide DNA methylation analysis in blood samples.

49 Whereas obesity was only marginally related to variability in DNA methylation pattern,

50 comparisons between lifestyle categories resulted in 145 Differentially Methylated Positions

51 (DMPs) and 4682 Differentially Methylated Regions (DMRs) annotated to 4426 unique genes.

52 Intersection analysis showed that diet, physical activity, smoking and alcohol intake are equally

53 contributing to the observed differences, which particularly affects pathways related to

54 glutamatergic synapse and axon guidance. DNA methylation patterns help discriminate

55 individuals with a healthy vs. unhealthy lifestyle, which may mask subtle methylation differences

56 derived from obesity.

57 Key words: lifestyle score - diet - physical activity - smoking - alcohol - epigenetics - DNA

58 methylation - epigenetic clock

61 Objective

62 Obesity is well recognized as a multifactorial disease in most modern societies, with not only

63 individuals' genetic background contributing to the disease burden, but also with a crucial role of

64 lifestyle and environment, strongly influencing epigenetic mechanisms controlling metabolic

65 processes ${ }^{1}$. However, common lifestyle intervention regimes vary greatly in structure and length

66 and, thus, in their individual success on weight reduction [reviewed in Aronica et al. ${ }^{2}$ ]. Observed 
medRxiv preprint doi: https://doi.org/10.1101/2021.12.16.21267895; this version posted December 17, 2021. The copyright holder for this preprint (which was not certified by peer review) is the author/funder, who has granted medRxiv a license to display the preprint in perpetuity.

It is made available under a CC-BY-NC-ND 4.0 International license .

67 direct effects e.g. on DNA methylation patterns after short-term lifestyle interventions are often

68 marginal ${ }^{2}$, which might be due to their short duration and low intensity ${ }^{3}$. Recent studies

69 demonstrated that successful short term weight loss interventions may reduce methylation age

70 (mAge) to the chronological age level ${ }^{4}$. Furthermore, DNA methylation patterns may predict the

71 success of lifestyle-induced weight loss ${ }^{5-7}$.

72 Comprehensive studies investigating the underlying interaction between genetics, epigenetics and

73 especially lifestyle are currently lacking. Therefore, we I) analyzed and compared the human blood

74 DNA methylation patterns between subjects living a healthy and those living an unhealthy

75 lifestyle. II) We further compared obese and non-obese subjects to identify DNA methylation

76 patterns, which are related to an obese phenotype despite a healthy lifestyle, or potentially

77 associated with a healthy (lean) phenotype in an allegedly unhealthy obesogenic environment. III)

78 We elucidated lifestyle specific effects on the epigenetic clock. IV) Finally, we investigated the

79 role of genetic variants cis to the identified target regions by meQTL (methylation quantitative

80 trait loci) analyses and addressed potential consequences of these changes on blood transcriptome

81 by matrix-eQTMs (expression quantitative trait methylations).

$83 \quad$ Research Design and Methods

84 Study population

85 The present analyses included participants of the LIFE-Adult study, a population-based cohort

86 focusing on lifestyle diseases ${ }^{8}$. The cohort is comprised of $\sim 10,000$ adult subjects aged from 18

87 to 80 years (mean \pm standard deviations $(\mathrm{SD})$ : age $=57.4 \pm 12.5$ years, $\mathrm{BMI}=27.3 \pm 4.9 \mathrm{~kg} / \mathrm{m}^{2}$ ) from

88 the region of Leipzig, Germany. All participants underwent an extensive phenotyping including

89 anthropometric measurements, social- and lifestyle-behavior questionnaires and blood parameters.

90 For most subjects, EDTA blood samples are available ${ }^{8}$. All participants gave written informed 
medRxiv preprint doi: https://doi.org/10.1101/2021.12.16.21267895; this version posted December 17, 2021. The copyright holder for this preprint (which was not certified by peer review) is the author/funder, who has granted medRxiv a license to display the preprint in perpetuity.

It is made available under a CC-BY-NC-ND 4.0 International license .

91 consent to participate in the study and procedures were approved by the University of Leipzig's

92 ethics committee (registration number: 263-2009-14122009) and conducted according to the

93 Declaration of Helsinki. Study participation, assessments and interviews were supervised and

94 carried out by trained staff and under supervised standard operation procedures ${ }^{8}$.

95 Lifestyle Score

96 We created a Lifestyle Score (LS) as sum of four different sub scores: diet, physical activity,

97 alcohol consumption and smoking 9 . To calculate the scores, we included data from four self-

98 reported questionnaires: I) a German version of the Food Frequency Questionnaire (FFQ) ${ }^{10}$, II)

99 the Short-Form International Physical Activity Questionnaire (SF-IPAQ) ${ }^{11}$, III) a questionnaire

100 about smoking status and quantity, as well as IV) about daily alcohol consumption and frequency.

101 The final LS ranged from 3 to 66 (mean \pm SD: 27.19 \pm 11.2 ), with low and high LS values

102 representing a healthy and unhealthy lifestyle, respectively. Detailed description of the individual

103 scoring as well as explanation of each sub-score can be found in Supplemental Material and

104 Supplemental Table 1. Subjects with any missing questionnaire item were completely excluded

105 from further analyses to avoid potential effects caused by general non-compliance of those

106 subjects. Similarly, participants with pre-existing diabetic conditions (HbA1c $\geq 6.5 \%)^{12}$ or missing

107 BMI measures were also excluded from subsequent analyses. A total of 4107 subjects (mean \pm SDs:

108 Age $=56 \pm 13$ years, $\mathrm{BMI}=27.0 \pm 4.7 \mathrm{~kg} / \mathrm{m}^{2}, \mathrm{LS}=27.19 \pm 11.02$ ) passed all criteria (Table 1).

109

110 Subset for genome-wide methylation and validation measurements

111 Based on the LS calculation we stratified the cohort into two groups reporting the most healthy

112 and unhealthy lifestyles, by selecting the lowest and highest five percent $\left(5^{\text {th }}\right.$ percentile $\mathrm{LS} \leq 11$;

$11395^{\text {th }}$ percentile $\mathrm{LS} \geq 48$ ). Within these groups ( $\left.N=234\right)$, we found 140 subjects with and 94 subjects 
medRxiv preprint doi: https://doi.org/10.1101/2021.12.16.21267895; this version posted December 17, 2021. The copyright holder for this preprint (which was not certified by peer review) is the author/funder, who has granted medRxiv a license to display the preprint in perpetuity.

It is made available under a CC-BY-NC-ND 4.0 International license .

114 without obesity according to BMI criteria ${ }^{13}$. Based on this and an equal age range (Supplemental

115 Figure 1b) we further selected 25 subjects without $\left(\mathrm{BMI}<25 \mathrm{~kg} / \mathrm{m}^{2}\right)$ and 25 subjects with obesity

$116\left(\mathrm{BMI}>30 \mathrm{~kg} / \mathrm{m}^{2}\right)$ amongst each subgroup $\left(5^{\text {th }} \mathrm{vs} .95^{\text {th }}\right.$ percentile $)(N$ total $=100)$ for the genome-

117 wide methylation discovery cohort and included all (with and without obesity) subjects with

118 sufficient available DNA $(N=213)$ for validation analysis. The discovery cohort comprised 44

119 males and 56 females with a mean BMI of $28.6 \pm 6.5 \mathrm{~kg} / \mathrm{m}^{2}$. The validation cohort $\left(N=213 ; 5^{\text {th }} / 95^{\text {th }}\right.$

120 percentile=100/113; lean/obese=131/82) included 84 males and 129 females with a mean BMI of

$121 \quad 27.1 \pm 6.2 \mathrm{~kg} / \mathrm{m}^{2}$ (Supplemental Table 2).

122

123 Sample preparation

124 All samples were isolated, stored and maintained at the Leipzig Medical Biobank ${ }^{14}$, according to

125 standard protocols. Briefly, blood samples were taken after an overnight fast (mean fasting

126 duration $12.7 \pm 1.7 \mathrm{~h}$ ) during the individuals' study visit and stored at $4-8{ }^{\circ} \mathrm{C}$ until DNA isolation

127 (within $48 \mathrm{~h}$ after blood withdrawal) on the Autopure LS platform (Qiagen, Germany) using

128 chemistry by Qiagen and Stratec Molecular (Stratec, Germany). Genomic DNA samples have been

129 stored at $-80^{\circ} \mathrm{C}$ prior integrity control using gel-electrophoresis and concentration measurements

130 of double stranded DNA using Quant-iT PicoGreen dsDNA (Invitrogen, ThermoFisher Scientific,

131 Germany) and Quantus (Promega, Germany) technologies.

132

133 Genome-wide DNA methylation analysis

134 500ng of genomic DNA was taken for bisulfite conversion using EZ DNA Methylation Gold Kit

135 (Zymo Research, Netherlands). After quality control, amplification, and hybridization on Illumina

136 HumanMethylation850 Bead Chips (Illumina, Inc., San Diego, CA, U.S.A) the Illumina iScan 
137 array scanner was used to quantify genome-wide DNA methylation levels at 850K CpG sites per

138 sample on single-nucleotide resolution.

139 Raw data was first quality controlled using the QC report of the minfi R package (v1.38.0) ${ }^{15,16}$.

140 Two samples, which do not pass the badSampleCutoff of 10.5, were excluded during

141 normalization steps. Beta densities and control probes were within predicted specifications. Probes

142 which did not passed detection $P$-value $\left(P_{\text {detect }}=0.01\right)$ in more than $1 \%$ of all 98 samples were

143 excluded from the analysis (17,375 probes). Cross-reactive probes (38,924 probes) ${ }^{17}$ and probes

144 containing known single nucleotide polymorphisms (SNPs) $(29,383$ probes) at the CpG site were

145 also filtered out applying the maxprobes (v0.0.2) and minfi R packages, respectively. In addition,

146 probes on sex chromosomes were removed from the analysis subset $(19,627$ probes), as sex

147 represents a larger source of variation in our methylation data. In total 760,550 probes remained

148 for the analysis. $\beta$-value generation and quantile normalization was computed using the minfi $\mathrm{R}$

149 package ${ }^{15,16}$ and adjusted for the sex specific batch effects (see Supplemental Figure 1a). Further,

150 we analyzed the cell type composition using the Houseman approach ${ }^{18-20}$ adapted to EPIC arrays

151 by Salas et al. ${ }^{20}$. Possible differences in cell type composition were (see Supplemental Figure 2)

152 analyzed using Wilcoxon tests in R. We corrected $\beta$-values for cell type composition in an attempt

153 to reduce noise ${ }^{20}$, although none of the cell type populations differed strongly between the

154 subgroups (low and high LS) (Supplemental Figure 2a) and the low and high LS subgroups in

155 individuals without and with obesity (Supplemental Figure 2b).

156 Differential methylation analyses were performed between subjects with extreme healthy and

157 unhealthy lifestyle (low vs. high LS/ $5^{\text {th }} v s .95^{\text {th }}$ percentile) as well as between participants without

$158\left(\mathrm{BMI}<25 \mathrm{~kg} / \mathrm{m}^{2}\right)$ and with obesity $\left(\mathrm{BM}>30 \mathrm{~kg} / \mathrm{m}^{2}\right)$ within each lifestyle subgroup. The established

159 R package limma (v3.48.3) was used for identifying differentially methylated CpG sites ${ }^{21}$. As the 
medRxiv preprint doi: https://doi.org/10.1101/2021.12.16.21267895; this version posted December 17, 2021. The copyright holder for this preprint (which was not certified by peer review) is the author/funder, who has granted medRxiv a license to display the preprint in perpetuity.

It is made available under a CC-BY-NC-ND 4.0 International license.

160 arrays were run on two lanes, the different array slides were included as covariates in the analyses

161 for DMPs and DMRs (Supplemental Figure 3). DMPs with an adj. $P$-value $<5 \%$ were defined as

162 differentially methylated. Differentially methylated regions (DMRs) were extracted applying

163 DMRcate (v2.6.0) ${ }^{22}$ which uses a Gaussian kernel smoothing to find patterns of differential

164 methylations independent of genomic annotation. Only DMRs with more than two CpG sites were

165 reported. DMRs with a min. smoothed FDR $<5 \%$ were defined as differentially methylated. DMRs

166 with a mean methylation difference $> \pm 2 \%$ were further annotated to $\mathrm{CpG}$ islands (CpG shores,

$167 \mathrm{CpG}$ shelves and inter-CGI) and gene context related regions (promoters, 5'UTRs, exons, introns,

168 3'UTRs and intergenic). Genomic annotation were performed using the annotatr R package

169 (v1.18.1) ${ }^{23}$, with respect to multiple annotations. To elucidate putative drivers of blood DNA

170 methylation, separate analysis with individual covariates (smoking, diet, physical activity, alcohol,

171 BMI and age) were performed. Intersection analysis for covariate specific effects on lifestyle

172 DMRs was performed using the UpsetR (v1.4.0) package ${ }^{24}$.

173

174 Methylation age- and telomere lengths- clocks

175 DNA methylation age (DNAmAge), corresponding DNAmAge acceleration differences according

176 to Horvath's clock (I and II), Levine's clock and the telomere lengths clock were estimated using

177 the R package methylclock v. $0.7 .5^{25}$.

178

179 KEGG-pathway overrepresentation

180 Candidate genes identified by significant DMRs (min. smoothed FDR $<5 \%$ ) characterizing

181 lifestyle specific methylation differences (healthy vs. unhealthy living subjects) and differences

182 between subjects without and with obesity were taken forward for a KEGG pathway over- 
medRxiv preprint doi: https://doi.org/10.1101/2021.12.16.21267895; this version posted December 17, 2021. The copyright holder for this preprint (which was not certified by peer review) is the author/funder, who has granted medRxiv a license to display the preprint in perpetuity.

It is made available under a CC-BY-NC-ND 4.0 International license .

183 representation test using clusterProfiler::enrichKEGG (v.3.18.1) ${ }^{26}$. Enrichment $P$-values were

184 adjusted using Benjamini-Hochberg correction and $\mathrm{FDR}<5 \%$ was considered as statistically

185 significant.

186

187 Validation of candidate CpGs

188 We selected two top candidate DMPs (Table 3, Supplemental Table 8) from our discovery cohort

189 (high LS vs. low LS) for additional validation using bisulfite sequencing. Briefly, 300ng of

190 genomic DNA were bisulfite converted using EpiTect Fast DNA Bisulfite Kit (Qiagen, Germany).

191 After a whole genomic amplification using the EpiTect Whole Bisulfitome Kit (Qiagen, Germany)

192 candidate regions were amplified and sequenced using the PyroMark Q24 platform and self-

193 designed assays for Retinoic Acid Receptor Alpha (RARA) and F2R Like Thrombin Or Trypsin

194 Receptor 3 (F2RL3) candidate DMPs (Qiagen, Germany). Primer sequences are shown in

195 Supplemental Table 3. All analyses were performed in duplicates including two non-template

196 controls per sequence run.

\section{Transcriptome data}

199 Transcriptome data was available from Illumina HT-12 v4 Expression BeadChips (Illumina, San

200 Diego, CA, USA) using whole blood RNA samples from the LIFE-Adult cohort as described

201 elsewhere ${ }^{8,27}$. Data processing was performed using R/Bioconductor after extraction of all 47,231

202 gene-expression probes using the Illumina GenomeStudio without background correction. Further,

203 expression values were $\log$ 2-transformed, quantile-normalized ${ }^{28,29}$ and batch effect correction was

204 performed using an empirical Bayes method ${ }^{30}$. Probes were excluded when expressed in less than

$2055 \%$ of the (subgroup-specific) samples (detected by Illumina GenomeStudio), still being associated 
with batch effects after Bonferroni-correction or not mapping to a gene accordingly ${ }^{31}$ (accessed on 2019-04-04). Additionally, gene probes without available annotation and genes on X and Y chromosomes were removed in order to effects introduced by sex. In summary 20,114 valid geneexpression probes were identified corresponding to 14,687 single genes in the human genome

211 detected gene-expression probes of a sample was required to be within \pm 3 interquartile ranges

212 (IQR) from the median, II), the Mahalanobis distance of several quality characteristics of each

213 sample (signal of AmbionTM ERCC Spike-In control probes, signal of biotin-control-probes,

214 signal of low-concentration control probes, signal of medium-concentration control probes, signal

215 of mismatch control probes, signal of negative control probes and signal of perfect-match control

216 probes) ${ }^{32}$ had to be within median $+3 \times$ IQR and III), Euclidean distances of expression values as

217 described ${ }^{29}$ had to be within 4 x IQR from the median. Overall, of the assayed 3,526 samples, 107

218 samples were excluded for quality reasons.

\section{Genotype data}

220 For genotypes, 7,838 participants of LIFE-Adult were genotyped using the genome-wide SNP 221 array Affymetrix Axiom CEU1 and the software Affymetrix Power Tools (version 1.20.6). Quality 222 control (QC) of the genotyped data was performed following Affymetrix's data analysis guide ${ }^{33}$ 223 as previously described ${ }^{34}$. Quality control according to Affymetrix's data analysis guide included 224 dish-QC (<0.82), sample call rate $(<97 \%)$, sex-mismatch, ambiguous relatedness (e.g. sample mix225 up) and abnormalities of XY intensity plots (e.g. XXY samples filtered for gonosomal analyses).

226 Genetic heterogeneity was evaluated with principal component analyses and outliers ( $>6$ SD in 227 any of the first 10 principal components) were removed. The criteria call rate, parameters of cluster 228 plot irregularities according to Affymetrix's recommendations, violation of Hardy-Weinberg 
medRxiv preprint doi: https://doi.org/10.1101/2021.12.16.21267895; this version posted December 17, 2021. The copyright holder for this preprint (which was not certified by peer review) is the author/funder, who has granted medRxiv a license to display the preprint in perpetuity.

It is made available under a CC-BY-NC-ND 4.0 International license .

229 equilibrium $\left(P\right.$-value $\left.<10^{-6}\right)$ in an exact test for autosomes, $\left(P\right.$-value $\left.<10^{-4}\right)$ for chromosome $\mathrm{X}$ with

230 women only ${ }^{35}$ and batch association $\left(P\right.$-value $\left.<10^{-7}\right)$ were considered during SNP QC.

231 Subsequently, 7669 samples and 532,676 SNPs were imputed on the reference 1000 Genomes

232 Phase $3^{36}$, applying SHAPEIT ${ }^{37}$ v2r900 (prephasing) and IMPUTE2 ${ }^{37,38}$ v2.3.2 for genotype

233 estimation. A specific genotype was assigned to a SNP if its corresponding genotype estimation

234 featured a probability of $>=0.8$. In $2.5 \%$ of the cases, none of the genotypes exceeded that threshold 235 and the respective SNP was labeled "missing" for that sample. SNPs whose "missing"-count over

236 all samples exceeded upper quartile+1.5*IQR were removed resulting in a total of 2830 SNPs.

\section{7 matrixEQTL Analysis}

238 Among samples with significant DMP data (from DMRs healthy vs. unhealthy), additional gene

239 expression and SNP data was available for 48 samples. The R package matrixEQTL v2.3 ${ }^{39}$ was

240 employed on all three pairs of datasets in order to identify cis effects (within a range of $+/-1 \mathrm{~kb}$ )

241 between methylation and expression (eQTMs), methylation and SNPs (meQTLs) and expression

242 and SNPs (eQTLs). All three comparisons were performed on the complete data $(N=48)$ and both

243 subgroups with high LS $(N=23)$ and low LS $(N=25)$ separately. Since sex batch effects have been

244 adjusted for in both expression and methylation data, small batch effects remained only for age

245 and BMI. However, including both age and BMI as covariates into the matrixEQTL analysis did

246 not change the overall result which is why the final matrixEQTL analysis was run without

247 considering any covariances. 
medRxiv preprint doi: https://doi.org/10.1101/2021.12.16.21267895; this version posted December 17, 2021. The copyright holder for this preprint (which was not certified by peer review) is the author/funder, who has granted medRxiv a license to display the preprint in perpetuity.

It is made available under a CC-BY-NC-ND 4.0 International license .

250 All statistical analysis were performed using $R$ software version $4.0 .4^{40}$. After checking for normal

251 distribution, Mann-Whitney U-Test or Welch`s t-test was applied to test for differences between

$2525^{\text {th }}$ and $95^{\text {th }}$ percentile as well as between lean and obese subgroups for the following phenotypes:

253 BMI, age, HbA1c, waist-to-hip ratio (WHR), fasting plasma glucose and insuline, Low Density

254 Lipoprotein (LDL)-, High Density Lipoprotein (HDL)-, apolipoprotein A1- and triglyceride serum

255 levels. Welch`s t-test was used to compare methylation differences measured as normalized B-

256 values between low LS vs. high LS for each top DMP, respectively. Using first Shapiro-Wilk-test

257 to proof normal distribution of the bisulfite sequencing data, independent Mann-Whitney U-Test

258 was applied to compare methylation differences within the validation cohort. Methylation levels

259 between BMI categories were compared applying 2-way ANOVA. Correlation analysis were

260 performed using Spearman`s correlation. All respective analysis were adequately corrected for

261 multiple testing.

262

$263 \underline{\text { Results }}$

264 Self-reported lifestyle reflects obesity specific phenotypes

265 We correlated the Lifestyle Score (LS) with BMI and WHR in 4107 LIFE-Adult participants. The

266 LS was related to the obesogenic environment (Supplemental Figure $4 \mathrm{a}-\mathrm{b})\left(\right.$ all $P$-value $<1 \times 10^{-3}$ )

267 with significantly higher values in subjects with obesity (Supplemental Figure 4c). We furthermore

268 demonstrated that all individual scores (diet, PA, smoking, alcohol and total LS) were mutually

269 dependent (Supplemental Figure 4d), which was particularly marked in the extreme subgroups $\left(5^{\text {th }}\right.$

270 and $95^{\text {th }}$ percentile, Supplemental Figure 4e). Finally, our score showed simultaneous negative

271 correlations (all $P$-value $<1 \times 10^{-15}$ ) to the protective lipid parameters HDL-C and apolipoprotein

272 A1, which were higher in healthy living subjects (Supplemental Figure 5a-b). 
273 When comparing healthy $v s$. unhealthy subgroups $\left(5^{\text {th }}\right.$ vs. $95^{\text {th }}$ percentile LS, healthy LS: $N=216$,

274 unhealthy LS: $N=207$ ), nominal differences were observed regarding BMI distribution

275 (Supplemental Figure 5, Table 1) (N lean/overweight/obese: healthy LS-73/95/48, unhealthy LS-

276 67/93/46; $P=0.051)$. Although HbA1c, fasting plasma glucose, fasting plasma insulin and LDL

277 serum levels did not differ between the two groups either (all $P$-value $>0.05$, Table 1 ), strong

278 differences were found for waist circumference $\left(P\right.$-value $\left.<3 \times 10^{-6}\right)$, age, Apo A1 and triglyceride

279 serum levels (all $P$-value $\left.<1 \times 10^{-9}\right)$ and especially HDL levels $\left(P\right.$-value $\left.<1 \times 10^{-15}\right)$ and WHR $(P$ -

280 value $\left.<2.2 \times 10^{-16}\right)$. Subjects living an extreme healthy lifestyle were older (mean age difference $=$

2816 years) with lower WHR (mean WHR difference $=0.08)$ and prominently lower lipid serum

282 levels. However, as expected, all phenotypes differed significantly between subjects with and

283 without obesity within healthy and unhealthy subgroups (all $P$-value $<2 \times 10^{-2}$ ) respectively, except

284 for fasting plasma LDL. Regarding sex distribution, it is noticeable that females are

285 overrepresented in the healthy subgroup, whereas males (Table 1) dominate the unhealthy

286 subgroup.

288 DNA methylation signatures are related to individuals' lifestyle

289 By comparing genome-wide blood DNA methylation pattern in subjects with healthy vs. unhealthy

290 lifestyle we identified 4682 significant DMRs annotated to 4426 genes with a min. smoothed

291 FDR $<5 \%$, which included 220 DMRs with FDR $<1 \times 10^{-4}$ (Supplemental Table 4, Figure 1a).

292 Amongst the significant DMRs the mean methylation level differences range from $-6.9 \%$ to $5.5 \%$.

293 Given the rather subtle methylation changes for the majority of the DMRs, we introduced a mean

294 methylation threshold of $>2 \%$ to further narrow down the potential causal candidate DMRs.

295 Among the 340 DMRs reaching this cut off, 164 DMRs were hypermethylated (mean methylation 
medRxiv preprint doi: https://doi.org/10.1101/2021.12.16.21267895; this version posted December 17, 2021. The copyright holder for this preprint (which was not certified by peer review) is the author/funder, who has granted medRxiv a license to display the preprint in perpetuity.

It is made available under a CC-BY-NC-ND 4.0 International license .

296 difference \pm SD:2.6\% $\pm 0.6 \%$ ), whereas 176 DMRs were hypomethylated (mean methylation

297 difference \pm SD:- $2.8 \% \pm 0.8 \%$ ) in healthy compared to unhealthy living individuals (Figure 1a,

298 Supplemental Table 4). Taking into account a DMR can have more than one annotation, most

299 DMRs (46\%; counts relative to the number of DMRs) were located in CpG-islands, followed by

$30045 \%$ located in CpG-shores. In relation to gene regions, most DMRs are located in introns (59\%),

301 followed by exons (39\%) (Figure 1b).

302 The top 15 hypo- and hyper-methylated significant DMRs according to their mean methylation

303 difference are presented in Table 2 with a DMR annotated to the Glutamine-Fructose-6-Phosphate

304 Transaminase 2 (GFPT2) gene locus showing the strongest hypomethylation (mean methylation

305 difference DMR=-6.9\%). A DMR annotated to the Glutamate Rich 1 (ERICHI) gene showed the

306 strongest hypermethylation (mean methylation difference DMR=5.4\%). Finally, using KEGG

307 pathway analyses we identified the glutamatergic synapse as the most enriched pathway (adj. $P$ -

308 value $<0.01$ ) followed by axon guidance, another brain related pathway (adj. $P$-value $<0.05$ ). Most

309 of the nine enriched pathways (Supplemental Table 5 and Figure 1c) are related to various cancer

310 types.

311 As demonstrated by the intersection plot (Figure 1d, Supplemental Table 6) the majority of the

312 DMRs ( $N=1952)$ are driven by all 4 lifestyle subscores together (diet, PA, smoking and alcohol),

313 followed by a combination of them together with BMI and age ( $N=743$ ). Obviously, BMI and age

314 alone do not explain any of the identified DMRs. Although, this did not indicate a prominent role

315 of smoking (Figure 1d), given by the nature of the lifestyle score a comparison between

316 participants with very healthy and very unhealthy lifestyle mirrors differences between non-

317 smokers and smokers. We therefore further adjusted the complete analyses for smoking as

318 covariate, which resulted in 629 identified DMRs with a min. smoothed FDR $<5 \%$. Amongst them, 
medRxiv preprint doi: https://doi.org/10.1101/2021.12.16.21267895; this version posted December 17, 2021. The copyright holder for this preprint (which was not certified by peer review) is the author/funder, who has granted medRxiv a license to display the preprint in perpetuity.

It is made available under a CC-BY-NC-ND 4.0 International license .

319 the most significant DMR is located within a CpG Island of the Ring Finger Protein 39 (RNF39)

320 locus (Supplemental Table 7).

321

322 Lifestyle-derived DMPs correlate with metabolic traits related to obesity

323 DMP-specific analysis comparing subjects with healthy and unhealthy lifestyle identified 145

324 significant DMPs (adj. $P$-value $<5 \%$ ) (Figure 2a, Supplemental Table 8). A total of 26 DMPs

325 passed a mean methylation change $|(\log F C)| \geq 5 \%, 14$ of which were hypermethylated $\operatorname{logFC} \geq 5 \%$

$326(0.07 \pm 0.04)$ while 12 showed hypomethylation $\log \mathrm{FC} \leq-5 \%(-0.06 \pm 0.01)$. Of these, 19 DMPs were

327 clearly assigned to a specific gene. However, when considering significance levels (adj. $P$ -

328 value $<5 \%$ ) as well as mean methylation change $\geq 5 \%$, the strongest effects were observed for

329 AHRR (Aryl-Hydrocarbon Receptor Repressor), F2RL3 (F2R Like Thrombin or Trypsin Receptor

330 3), RARA (Retinoic Acid Receptor Alpha), and PRSS23 (Serine Protease 23) (Figure 2b, all P-

331 value $<1 \times 10^{-11}$, Supplemental Table 8 ), all of them being hypomethylated under unhealthy

332 conditions. Correlation analysis between the identified DMPs and obesity related phenotypes

333 (HbA1c, LDL, HDL, blood glucose, insulin, apolipoprotein A1, triglycerides, BMI, waist

334 circumference, WHR and age) as well as the LS and its subscores can be found in Supplemental

335 Table 9. Two of the 20 included DMPs showed significant correlation with WHR even after

336 Bonferroni correction, although no SNPs within the genomic region have been shown to be

337 associated for BMI-adjusted WHR in previous GWAS ${ }^{41}$ (GWAS catalog accessed June 2021).

338 Amongst the identified DMPs the strongest correlation to WHR was found for Vasohibin 1

$339(V A S H 1)\left(P\right.$-value $\left.=4.2 \times 10^{-5}, \mathrm{r}=-0.4\right)$, which is in line with an association to HbAlc $(\%)(P-$

340 value $=0.03, \mathrm{r}=-0.21)$, triglycerides $(\mathrm{mmol} / \mathrm{l})(P$-value $=0.046, \mathrm{r}=-0.2)$ and waist circumference

$341(\mathrm{~cm})(P$-value $=0.04, \mathrm{r}=-0.2)$, although only the association with WHR sustained after correction 
medRxiv preprint doi: https://doi.org/10.1101/2021.12.16.21267895; this version posted December 17, 2021. The copyright holder for this preprint (which was not certified by peer review) is the author/funder, who has granted medRxiv a license to display the preprint in perpetuity.

It is made available under a CC-BY-NC-ND 4.0 International license .

342 for multiple testing. Finally, two DMPs of F2RL3, one of our selected top hits, showed marginal

343 correlations to LDL serum levels (all $P$-value $<0.03 ; \mathrm{r}=-0.22)$ and triglycerides (mmol/l) (all $P$ -

344 value $<0.07, \mathrm{r}=-0.27)$ and one DMP additionally to HbA1c $(\%)(P$-value $<0.01, \mathrm{r}=-0.3)$. The

345 selected top DMPs for $F 2 R L 3$ showed additional correlations to HDL (mmol/l) $(P=0.03, \mathrm{r}=0.23)$

346 and apolipoprotein A1 $(\mathrm{g} / \mathrm{l})(P=0.03, \mathrm{r}=0.23)$, albeit not withstanding corrections for multiple

347 testing.

348 In summary, 13 of the 20 selected DMPs showed marginal correlations with triglycerides (all $P$ -

349 value<0.046), 8 with HDL (all $P$-value<0.047) and 7 with LDL (all $P$-value<0.033) serum levels

350 (Supplemental Table 9).

352 Bisulfite sequencing within RARA and F2RL3 loci supports findings from the discovery stage

353 Based on these findings and further supported by previously reported data ${ }^{42-44}$, we selected two

354 DMPs (F2RL3:cg03636183 and RARA:cg17739917) for validation $(N=213)$ using bisulfite

355 sequencing and demonstrate directionally consistent differences between subjects with healthy vs.

356 unhealthy lifestyle (Figure 2c-d; both $P$-value<0.001, mean meth. diff.: $R A R A \quad \mathrm{CpG}=8.37 \%$,

357 F2RL3 CpG2=13.87\%). Furthermore, the surrounding $\mathrm{CpG}$ position confirmed this effect with all

$358 P$-value $<0.01$ and a mean methylation difference of $>5.59 \%$ (mean meth. diff.: $R A R A$

$359 \mathrm{CpG} 2=11.99 \%, R A R A$ CpG3=12.58\%, F2RL3 CpG1=5.59\%, F2RL2 CpG3=13.2\%) (Figure 2c-

360 d). The here used validation cohort did not differ significantly from the discovery cohort regarding

361 age, BMI and sex distribution (Table 1). Spearman's correlation analysis showed a significant

362 correlation between methylation levels observed in the genome-wide methylation analysis and

363 bisulfite sequencing (RARA: spearman's r=0.45, F2RL3: spearman's $\mathrm{r}=0.53$, both $P<7.9 \times 10^{-5}$ )

364 (Supplemental Figure 5c-d). 
medRxiv preprint doi: https://doi.org/10.1101/2021.12.16.21267895; this version posted December 17, 2021. The copyright holder for this preprint (which was not certified by peer review) is the author/funder, who has granted medRxiv a license to display the preprint in perpetuity.

It is made available under a CC-BY-NC-ND 4.0 International license .

Obesity specific methylation marks

367 Driven by the comparable distribution of subjects with and without obesity between very healthy

368 and unhealthy lifestyle groups, we aimed to identify lifestyle independent obesity-related

369 methylation marks. Therefore, blood methylation patterns of subjects with obesity $(N=25)$ were

370 compared with subjects without obesity $(N=25)$ within each lifestyle group separately.

371 Interestingly, whereas about 1572 DMRs annotated to 1599 different genes were identified in

372 healthy subjects, only 85 DMRs annotated to 101 genes were detected in subjects living an

373 unhealthy lifestyle (Supplemental Table 10 and 11) with a min. smoothed FDR $<5 \%$. This further

374 included 10 identical annotations amongst the PAX6 and HOXA9-10 gene clusters, already known

375 candidates regarding obesity and related co-morbidities. However, on CpG levels no DMPs

376 sustained after correction for multiple testing (data not shown). Nevertheless, KEGG pathway

377 analysis for the healthy subgroup indicated eight enriched pathways, amongst them GABAergic

378 synapse, dilated cardiomyopathy and calcium signaling (Supplemental Figure 6, Supplemental

379 Table 12), whereas for the unhealthy subgroup only antigen processing and presentation was

380 enriched (not shown).

382 Methylation Age

383 We observed the strongest association $\left(P\right.$-value $<1 \times 10^{-10}, \mathrm{R}^{2}=0.37$, Figure $\left.2 \mathrm{e}\right)$ between methylation 384 age and subjects' chronological age within the discovery cohort for the Horvath's clock II, which 385 was compared to Horvath's I, additionally trained on 850K EPIC arrays (Supplemental Figure 7a386 c). Only marginal $(P$-value $=0.01)$ differences in DNAmAge acceleration were observed when 387 comparing individuals with healthy vs. unhealthy lifestyle, which was similar to comparing never 
medRxiv preprint doi: https://doi.org/10.1101/2021.12.16.21267895; this version posted December 17, 2021. The copyright holder for this preprint (which was not certified by peer review) is the author/funder, who has granted medRxiv a license to display the preprint in perpetuity.

It is made available under a CC-BY-NC-ND 4.0 International license .

388

389

390

391

392

393

394

395

396

397

398

399

400

401

402

403

404

405

406

407

408

409

410

smokers with previous or current smokers (Supplemental Figure 7d and f). No difference was observed between subjects with and without obesity (Supplemental Figure 7e). We furthermore observed a strong negative association between the telomere lengths clock and chronological age $\left(P\right.$-value $<1 \times 10^{-8}, \mathrm{R}^{2}=-0.32$, Figure $\left.2 \mathrm{e}\right)$. Interestingly, both clocks showed an additional linear association to WHR within our discovery cohort (all $P$-value $<1 \times 10^{-4}$, Figure $2 \mathrm{e}$ ).

\section{Underlying genetic predispositions and effects on mRNA level in blood}

Driven by the small overlapping sample size $(N=48)$ and only marginal genetic variation in close proximity $(+/ 1 \mathrm{~kb})$ to the identified target DMRs (healthy vs. unhealthy lifestyle) we could not identify any meQTLs or eQTLs. However, we found associations between methylation levels of 8 DMPs with target mRNA expression levels (Supplemental Table 13) in the combined discovery group (all individuals with healthy and unhealthy lifestyle). Amongst them, only two eQTMs annotated to the ANPEP (Alanyl Aminopeptidase) locus sustained after correction for multiple testing (matrix FDR=0.03; Supplemental Table 13; Supplemental Figure 8). Four eQTMs were detected in subjects with healthy and 8 with unhealthy lifestyle, amongst them also one of our candidate DMP of F2RL3 in healthy subjects.

\section{$\underline{\text { Discussion }}$}

Epigenetic markers are known to reflect environmental conditions and thereby are not only affected by genetic predisposition, but most strongly by our daily lifestyle. Although this is widely acknowledged by the scientific community, the majority of epigenetic studies in regard to obesity, most of them conducted cross-sectionally, are still lacking the inclusion of relevant lifestyle drivers 45. Therefore, to the best of our knowledge, this is one of the few studies investigating potential 
411 effects of lifestyle on the respective blood DNA methylation signatures ${ }^{46}$. Here, we calculated LS

412 scores based on each individuals' diet, physical activity, smoking, and alcohol consumption within

413 the LIFE-Adult study from Germany. Genome-wide DNA methylation analysis in blood samples

414 of 100 subjects representing healthy and unhealthy lifestyle extremes demonstrated that daily

415 lifestyle is most likely superior to the obesity state itself in associations with blood DNA

416 methylation pattern, as supported by association studies between neonatal blood methylation and

417 the risk to develop obesity later in life ${ }^{47}$. The study showed that the distribution of obesity

418 categories in extreme lifestyle groups was comparable, and that potentially obesity-associated

419 methylation marks were more frequent in subjects with healthy lifestyle. Furthermore, methylation

420 age and estimated telomere length showed strong correlations to chronological age and WHR, with

421 observed smaller DNAmAge acceleration distances in healthy subjects. Finally, two DMPs for

422 ANPEP also showed the strongest eQTM in blood.

424 With this study, we took several lifestyle aspects into account to explore relations between long-

425 term lifestyle habits and differences in human blood methylation patterns. Our findings imply that

426 dietary habits, physical activity, smoking habits and alcohol consumption are influencing

427 epigenetic patterns together, whereas only neglectable effects are attributed to age and BMI alone.

428 This suggests that rather than simply representing the consequence of obesity, differences in blood

429 derived methylation marks may be primarily driven by long-term lifestyle habits. This is further

430 supported by observed smaller DNAmAge acceleration in healthy compared to unhealthy lifestyle

431 group, whereas no significant difference could be observed between subjects with and without

432 obesity. 
433 We identified several candidate genes differentially methylated according to the LS and

434 successfully validated $R A R A$ and $F 2 R L 3$, already known from previous studies to be influenced

435 by lifestyle aspects and acknowledged for their role in metabolic diseases ${ }^{42,44,48}$. Both genes were

436 hypermethylated within extremely healthy compared to unhealthy living individuals, which is in

437 line with previously published data ${ }^{42,49,50}$. In particular, hypomethylation of the DMP within the

438 F2RL3 locus appears to increase the risk for cardiovascular as well as overall mortality ${ }^{42,49}$.

439 Translated to our results this might indicate an increasing mortality risk of an unhealthy lifestyle

440 accompanied with associated diseases such as obesity, type 2 diabetes, cardiovascular diseases or

441 cancer. Previous studies further showed a hypomethylating effect of smoking on the here identified

442 F2RL3 DMP ${ }^{48}$. Moreover, very recently a strong association to coffee consumption in a large-

443 scale EWAS was reported ${ }^{51}$. Consistent with published data on smoking, subjects with unhealthy

444 lifestyle in our study showed a mean methylation of $67 \%$ compared to $81 \%$ in the healthy lifestyle

445 group, with the majority of subjects within the unhealthy group being actual smokers (validation

446 cohort $)$. In line with this we further observed a marginal $(P$-value $=0.04)$ positive correlation

447 between this methylation of this DMP and F2RL3 mRNA levels in the healthy lifestyle subgroup.

448 We found significant methylation differences between the healthy and unhealthy lifestyles for

$449 R A R A$, known for its role in adipogenesis ${ }^{52}$. It is noteworthy though, that based on the findings of

450 the present study, an increase in RARA methylation pattern might be related to higher HDL-C and

451 lower triglyceride serum levels, indicating a link between RARA and lipid metabolism.

452 Although the observed differences in DNA methylation in RARA could also be driven by smoking

453 as previously described ${ }^{43}$ and supported by the here found strong correlation with smoking, there

454 is still a prominent influence of other environmental conditions like diet and physical activity as

455 shown by our present data. Nevertheless, it needs to be acknowledged that in line with our study, 
medRxiv preprint doi: https://doi.org/10.1101/2021.12.16.21267895; this version posted December 17, 2021. The copyright holder for this preprint (which was not certified by peer review) is the author/funder, who has granted medRxiv a license to display the preprint in perpetuity.

It is made available under a CC-BY-NC-ND 4.0 International license .

456 the majority of methylation studies on smoking, although lacking any information on diet or

457 activity, identified a similar set of top candidates especially including F2RL3, RARA and AHRR in

458 human blood cells ${ }^{42,44,49,50}$. It is also worth to mention, that smoking effects on $F 2 R L 3$ methylation

459 were previously also observed in adipose tissue ${ }^{44}$. Consequently, narrowing down our list of

460 potential lifestyle discriminating candidates regions by including an additional adjustment for

461 smoking resulted in identification of a top DMR on chromosome 6 annotated to the Ring Finger

462 Protein 39 (RNF39). This DMR is overlapping a larger region very recently described to

463 successfully discriminate responder from non-responder to an lifestyle intervention based on either

464 Mediterranean/low-carbohydrate or low-fat diet with or without physical activity ${ }^{7}$.

466 There are a few key limitations to our study. First, we used a scoring system based on self-reported 467 questionnaires, which might lead to euphemistic information including over- or underestimation 468 of the real status ${ }^{53}$. However our study design is supported and strengthened by findings, which 469 are in line with previously reported data e.g. on lifestyle factors such as smoking ${ }^{42,44}$. Finally, the 470 observational and cross-sectional nature of the study does not allow testing the direction of 471 causality at least between methylation and metabolic phenotypes and limits our ability to rule out 472 confounding (e.g. sex), even though it seems unlikely that methylation marks affect lifestyle habits.

473 Although the identification of reliable and reproducible epigenetic marks for obesity in human 474 blood remains challenging, our study clearly indicates the importance of considering as many 475 lifestyle aspects as possible when analysing epigenetic data with regard to complex diseases like 476 obesity. We successfully demonstrate that the majority of $\mathrm{CpG}$ methylation marks are much 477 stronger influenced by our daily lifestyle than the obesity state itself.

\section{$\underline{\text { Declarations: }}$}


medRxiv preprint doi: https://doi.org/10.1101/2021.12.16.21267895; this version posted December 17, 2021. The copyright holder for this preprint (which was not certified by peer review) is the author/funder, who has granted medRxiv a license to display the preprint in perpetuity.

It is made available under a CC-BY-NC-ND 4.0 International license .

\section{Acknowledgements}

481 We thank all study participants of the LIFE Adult study whose personal dedication and 482 commitment have made this project possible. We would like to acknowledge excellent technical 483 assistance by Beate Gutsmann and Ines Müller.

485 Author contributions

486 MK, PK, PWF and MSc initiated, conceived and designed the study. IK and MK performed

487 lifestyle analysis, selected samples and wrote the first manuscript draft. IK performed DNA quali488 and quantification and performed most of the laboratory work. AH, IK, TH, LM and MK 489 performed statistical and bioinformatic analysis. MSc, RB, JT and ML conducted the LIFE 490 population based study, collected the phenotypes and generated genome and transcriptome data. 491 LM, KR, AT, YB, MS, MB, MSc and PWF supported the critical data interpretation and reviewed 492 the manuscript. AH, PK and MK wrote the final manuscript version.

\section{Funding}

495 This work has been supported by a young investigator research fund from the Medical Faculty of 496 the University Leipzig, by the German Diabetes Association, the Free State of Saxony, Deutsches

497 Zentrum für Diabetesforschung and grants from the Deutsche Forschungsgemeinschaft (DFG, 498 German Research Foundation - Projektnummer 209933838 - SFB 1052; B03, B08, C01, Z04; 499 SPP 1629 TO 718/2- 1).

500 LIFE-Adult is funded by the Leipzig Research Center for Civilization Diseases (LIFE). LIFE is an 501 organizational unit affiliated to the Medical Faculty of the University of Leipzig. LIFE is 
medRxiv preprint doi: https://doi.org/10.1101/2021.12.16.21267895; this version posted December 17, 2021. The copyright holder for this preprint (which was not certified by peer review) is the author/funder, who has granted medRxiv a license to display the preprint in perpetuity. It is made available under a CC-BY-NC-ND 4.0 International license .

502 funded by means of the European Union, by the European Regional Development Fund (ERDF)

503 and by funds of the Free State of Saxony within the framework of the excellence initiative.

504

\section{Consent for publication}

$506 \quad$ Not applicable

508 Availability of data and materials

509 All data generated or analyzed during this study are included in this published article and its

510 supplementary information files. Raw data will be made available via the Leipzig Health Atlas

511 after acceptance of the publication.

512

\section{Competing interests}

514 MB received honoraria as a consultant and speaker from Amgen, AstraZeneca, Bayer, Boehringer-

515 Ingelheim, Lilly, Novo Nordisk, Novartis, and Sanofi. All other authors declare no competing 516 interests. 
Tables:

519 Table 1 - Study Characteristics: Phenotypic data are described for all in the Lifestyle Score (LS)

Figure 2 - Differentially Methylated Positions (DMPs) comparing healthy vs. unhealthy lifestyle in the discovery (a-b) and the validation cohort (c-d): analysis included LIFE-adult subjects as well as for the healthy $\left(\leq 5^{\text {th }}\right.$ percentile) and unhealthy ( $\geq 95^{\text {th }}$ percentile) living extreme subgroups as mean \pm SD (incl. discovery and validation cohort; detailed in Supplemental Table 2). $P$-values show significant differences between healthy and unhealthy subgroups.

Table 2 - Top lifestyle-specific Differentially Methylated Regions (DMRs): Included are the top 15 significantly hyper- and hypo methylated DMRs (min. smoothed FDR $<5 \%$ ) between healthy and unhealthy living subjects.

Table 3 - Top lifestyle-specific Differentially Methylated Positions (DMPs): Included are the top 10 significantly hyper- and hypo methylated DMPs (adj. $P$-value<0.05) between healthy and unhealthy living subjects. Our selected candidates for the bisulfite validation are highlighted.

\section{Figures:}

Figure 1 - Lifestyle-specific Differentially Methylated Regions (DMRs) in the discovery cohort: a) Volcano plot representing the significant DMRs (min. smoothed FDR $<5 \%$ ) based on the healthy $v s$. unhealthy lifestyle comparison. Positive mean methylation differences $\geq|2| \%$ represent hypermethylated DMRs (red dots) and negative methylation difference $\geq|2| \%$ hypomethylation DMRs (blue dots) in the healthy subgroup. b) The location of the DMRs in relation to $\mathrm{CpG}$ islands (top) and the location of the DMRs in relation to gene regions (bottom). Both plots are presented as number of counts including multiple annotations. Hyper: hypermethylation, hypo: hypomethylation. c) KEGG pathway enrichment analysis presented as percentage of annotated genes relative to all genes involved in the respective pathway (hits in \%) for all enriched pathways with an FDR $<5 \%$. d) Intersection plot illustrating the frequency of significant DMRs driven by any of the included lifestyle aspect (diet, physical activity, smoking and alcohol) and the potential confounders age and BMI. The majority of the DMRs are driven by an interaction between all four lifestyle aspects.

a) Volcano plot representing the significant DMPs (min. smoothed FDR $<5 \%$ ) based on the healthy vs. unhealthy lifestyle comparison. Positive mean methylation differences $\geq|5| \%$ represent hypermethylated DMPs (red dots) and negative methylation difference $\geq|5| \%$ hypomethylation DMPs (blue dots) in the healthy subgroup. b) Box plots representing mean methylation \pm SD for the top four identified genes: RARA (cg17739917); F2RL3 (cg03636183); AHRR (cg05575921); PRSS23 (cg14391737) comparing healthy (low Lifestyle Score (LS)) vs unhealthy (high LS) living subjects, $95 \%$ confidence interval is represented by notches. $P$-values indicate statistically significant differences detected using Welch's t-test. c-d) Box plots are given as mean methylation $\pm \mathrm{SD}$ as well as the $95 \%$-confidence interval is represented by notches for the two validated DMPs (c) $R A R A$ and d) F2RL3) and their surrounding CpGs. $P$-values indicate statistical significance between healthy (low LS) and unhealthy (high LS) subjects detected using ANOVA. 
$P$-values are indicated as: $*<0.05, * *<0.01$ and $* * *<0.001$ e) Linear regression analysis between methyl age (methAge) for the Horvarth II, telomere length, chronological age and Waist-to-Hip Ratio (WHR) measurements presented as scatter plot. The light grey area represents the $95 \%$ confidence interval and $\mathrm{R}^{2}$ representing the coefficient of determination.

\section{Supplements (online only):}

\section{Supplemental Material - Lifestyle sub-scores}

\section{Supplemental Figures}

Supplemental Figure 1 - sex and age specific quality control: a) Principal Component Analysis (PCA) of the Illumina 850K methylation arrays. After sex normalization, no batch effect for sex is visible anymore, but the separation for the healthy (high) and unhealthy (low) living subjects is evident. b) Estimation plot using an unpaired t-test for age differences between low vs. high LS (healthy vs. unhealthy) subgroups.

Supplemental Figure 2 - Cell type distribution: Box plots representing the cell type proportions for a) low and high Lifestyle Score (LS) subgroups, and b) for low and high LS subgroups in individuals without (2) and with obesity (4) based on Illumina 850K methylation data. CD8 Tlymphocates (CD8T), CD4 T-lymphocytes (CD4T), natural killer cells (NK), B-lymphocytes (Bcell), monocytes (Mono) and neutrophils (Neu).

Supplemental Figure 3 - $\beta$-values densities of the Illumina $850 \mathrm{~K}$ methylation data: The densities of $\beta$-values are shown for a) the raw data and b) after adjustment for cell counts, array slides and gender. Since the arrays were run on two batches, differences are visible in the raw data and had to be corrected for.

Supplemental Figure 4 - Lifestyle Score (LS) associations in the LIFE cohort: Scatter dot plots representing spearman correlations between the LS and a) BMI in $\mathrm{kg} / \mathrm{m}^{2}$, b) Waist-to-hip ratio (WHR) for the total cohort $(\mathrm{N}=4107)$. c) Bar plot representing the $\mathrm{LS}$ values as mean \pm SEM for defined BMI categories. Intergroup differences were assessed using student's t-test; *: $P<0.05$. de) Correlations between lifestyle scores (including sub scores) are shown. LS and anthropometric measurements are presented as correlation matrix. Color and size of the dots represent Spearman's correlation coefficient $\mathrm{r}$; $\mathrm{p}$-values are indicated with $* * *: P<0.001, * *: P<0.01, *: P<0.05$. Figure d) total cohort $(\mathrm{N}=4107)$, e) significant correlations within the sub scores in the validation cohort consisting of the extreme lifestyle edges $(\mathrm{N}=213)$.

Supplemental Figure 5 - Lifestyle Score (LS) correlations in the total LIFE cohort ( $N=4107$ ): Scatter plots representing Spearman's correlations between the LS and a) High Density Lipoprotein (HDL)-Cholesterol serum levels $(\mathrm{mmol} / \mathrm{l})$ and b) Apolipoprotein A serum levels (mmol/l). Spearman's correlation analysis between methylation levels observed in the Illumina EPIC arrays and the pyrosequencing sequencing validation are shown in c) for the RARA and d) for the F2RL3 identified CpG position.

\section{Supplemental Figure 6 - KEGG pathway enrichment analysis of the healthy subgroup:} BMI related (non-obese vs. obese) KEGG pathway enrichment in the low Lifestyle Score (LS) subgroup is presented as hits in \% for all pathways with an FDR $<0.05$. 
610 Supplemental Figure 7 - Methyl age (MethAge) correlations in the discovery cohort:

611 Spearman correlation between MethAge for a) Horvath I, b) Horvath II and c) Levine's clock and 612 individuals chronological age in the discovery cohort $(N=100)$ presented as scatter dot plot. d-f) 613 Plots presenting differences in DNA methylation age (DNAmAge) acceleration as mean \pm SEM 614 between d) healthy and unhealthy living subjects, e) subjects without and with obesity and f) never615 vs. current/previous smokers.

Supplemental Figure 8 - Spearman's correlation between normalized methylation for ANPEP DMPs (cg23422008 and cg02008229) and corresponding normalized mRNA expression (ILMN_1763837) presented as scatter plot.

\section{Supplemental Tables}

Supplemental Table 1 - Detailed Scoring System: Diet Score was assessed using FFQinformation, favorable food intake got decreased scoring points with increased frequency, unfavorable food intake reached higher scores with regular consumption (high diet scores means unhealthy nutrition intake). Physical activity was rated via activity categories and MET-min/week divided into quartiles, counted by the SF-IPAQ (less active means higher scores). Smoking assessment is based on actual smoking status and information about pack years (higher nicotine consumption means higher scores). Alcohol consumption was considered harmful by the cut-offs based on DGE recommendations (exceeded consumption means higher scores).

Supplemental Table 2 - Study Characteristics of the subgroups: Phenotypic data is described for discovery and validation cohort subjects within the healthy ( $\leq 5^{\text {th. }}$ percentile) and unhealthy $\left(\geq 95^{\text {th }}\right.$ percentile) living extreme subgroups as mean \pm SD.

Supplemental Table 3 - Self-designed primer sequences: Self-designed primer sequences were used to validate candidate CpGs (F2RL34 and RARA) with pyrosequencing technique, based on the PyroMark Q24 platform.

Supplemental Table 4 - All lifestyle-specific Differentially Methylated Regions (DMRs): Overview of all significant (min. smothed FDR $<5 \%$ ) DMRs of the healthy vs. unhealthy lifestyle analysis. pathway overrepresentation analysis for Differentially Methylated Regions (DMRs) from the healthy vs. unhealthy Lifestyle-Score analysis. All significant DMRs were included. Enrichment $P$-values were adjusted using Benjamini-Hochberg correction and FDR $<5 \%$ were considered as statistically significant. 
Supplemental Table 7 - Lifestyle-specific Differentially Methylated Regions (DMRs) after smoking adjustment: Overview of all significant DMRs from the healthy vs. unhealthy lifestyle analysis with a min. smoothed FDR $<5 \%$ after additional adjustment for smoking score are shown.

\section{Supplemental Table 8 - All lifestyle-specific Differentially Methylated Positions (DMPs):} lifestyle study are given. Our selected candidates (F2RL34 and $R A R A)$ for the bisulfite validation are highlighted. correlation analysis: Correlation analyses between obesity-related phenotypes and the top 10 hyper- and hypomethylated DMPs between healthy vs. unhealthy lifestyle within the discovery cohort are given. $P$-values maintaining after correction for multiple testing [adj. $P$-values $<1.5 \times 10^{-}$ ${ }^{4} ; 0.05$ /(number included DMPs*number obesity-related phenotypes)], are indicated in bold.

\section{Supplemental Table 10 - Differentially Methylated Regions (DMRs) of subjects with healthy} lifestyle: Overview of all significant DMRs within subjects with healthy lifestyle comparing nonobese vs. obese phenotypes.

\section{Supplemental Table 11 - Differentially Methylated Regions (DMRs) of subjects with} unhealthy lifestyle: Overview of all significant DMRs within subjects with unhealthy lifestyle comparing non-obese vs. obese phenotypes.

\section{Supplemental Table 12 - KEGG pathway enrichment analysis of subjects with healthy} lifestyle: KEGG pathway overrepresentation analysis for Differentially Methylated Regions (DMRs) from non-obese vs. obese phenotypes in subjects with extreme healthy lifestyle. All DMRs with FDR $<5 \%$ were included. Enrichment $P$-values were adjusted using BenjaminiHochberg correction and only hits with an FDR $<0.05$ were considered statistically significant.

\section{Supplemental Table 13 - Expression Quantitative Trait Methylation Analysis (cis-eQTM):} cis-eQTM analysis for the combined discovery cohort and the healthy- and unhealthy lifestyle groups is given. All DMPs with a $P$-value $<0.05$ are listed including the corresponding T-test statistic and beta values as effect size estimates according to matrixEQTL, gene locus, strand and UCSC annotation. The associated expression probe is listed with its gene locus and annotation according to Illumina. The DMP $P$-values were adjusted using Benjamini-Hochberg correction and only hits with an FDR $<5 \%$ were considered statistically significant and are highlighted in bold

\section{References}

1. Rohde, K. et al. Genetics and epigenetics in obesity. Metabolism: clinical and experimental 92, 37-50; 10.1016/j.metabol.2018.10.007 (2019).

2. Aronica, L. et al. A systematic review of studies of DNA methylation in the context of a weight loss intervention. Epigenomics 9, 769-787; 10.2217/epi-2016-0182 (2017). 
3. McEwen, L. M. et al. DNA methylation signatures in peripheral blood mononuclear cells from a lifestyle intervention for women at midlife: a pilot randomized controlled trial. Applied physiology, nutrition, and metabolism = Physiologie appliquee, nutrition et metabolisme 43, 233-239; 10.1139/apnm-2017-0436 (2018).

4. Yaskolka Meir, A. et al. Lifestyle weight-loss intervention may attenuate methylation aging: the CENTRAL MRI randomized controlled trial. Clinical epigenetics 13, 48; 10.1186/s13148-021-01038-0 (2021).

5. Milagro, F. I. et al. A dual epigenomic approach for the search of obesity biomarkers: DNA methylation in relation to diet-induced weight loss. FASEB journal : official publication of the Federation of American Societies for Experimental Biology 25, 1378-1389; 10.1096/fj.10-170365 (2011).

6. Moleres, A. et al. Differential DNA methylation patterns between high and low responders to a weight loss intervention in overweight or obese adolescents: the EVASYON study. FASEB journal : official publication of the Federation of American Societies for Experimental Biology 27, 2504-2512; 10.1096/fj.12-215566 (2013).

7. Keller, M. et al. DNA methylation signature in blood mirrors successful weight-loss during lifestyle interventions: the CENTRAL trial. Genome medicine 12, 97; 10.1186/s13073-02000794-7 (2020).

8. Loeffler, M. et al. The LIFE-Adult-Study: objectives and design of a population-based cohort study with 10,000 deeply phenotyped adults in Germany. BMC public health 15, 691; 10.1186/s12889-015-1983-z (2015).

9. Lourida, I. et al. Association of Lifestyle and Genetic Risk With Incidence of Dementia. JAMA 322, 430-437; 10.1001/jama.2019.9879 (2019).

10. Steinemann, N. et al. Relative validation of a food frequency questionnaire to estimate food intake in an adult population. Food \& nutrition research 61, 1305193; 10.1080/16546628.2017.1305193 (2017).

11. Craig, C. L. et al. International physical activity questionnaire: 12-country reliability and validity. Medicine and science in sports and exercise 35, 1381-1395; 10.1249/01.MSS.0000078924.61453.FB (2003).

12. American Diabetes Association. Standards of medical care in diabetes-2010. Diabetes care 33 Suppl 1, S11-61; 10.2337/dc10-S011 (2010).

13. Chiu, M., Austin, P. C., Manuel, D. G., Shah, B. R. \& Tu, J. V. Deriving ethnic-specific BMI cutoff points for assessing diabetes risk. Diabetes care 34, 1741-1748; 10.2337/dc10-2300 (2011).

14. Baber, R. et al. Position Statement from the German Biobank Alliance on the Cooperation Between Academic Biobanks and Industry Partners. Biopreservation and biobanking 17, 372-374; 10.1089/bio.2019.0042 (2019).

15. Aryee, M. J. et al. Minfi: a flexible and comprehensive Bioconductor package for the analysis of Infinium DNA methylation microarrays. Bioinformatics (Oxford, England) 30, 1363-1369; 10.1093/bioinformatics/btu049 (2014). 
16. Fortin, J.-P., Triche, T. J. \& Hansen, K. D. Preprocessing, normalization and integration of the Illumina HumanMethylationEPIC array with minfi. Bioinformatics (Oxford, England) 33, 558-560; 10.1093/bioinformatics/btw691 (2017).

17. Chen, Y. et al. Discovery of cross-reactive probes and polymorphic CpGs in the Illumina Infinium HumanMethylation450 microarray. Epigenetics 8, 203-209; 10.4161/epi.23470 (2013).

18. Houseman, E. A. et al. DNA methylation arrays as surrogate measures of cell mixture distribution. BMC bioinformatics 13, 86; 10.1186/1471-2105-13-86 (2012).

19. Kaushal, A. et al. Comparison of different cell type correction methods for genome-scale epigenetics studies. BMC bioinformatics 18, 216; 10.1186/s12859-017-1611-2 (2017).

20. Salas, L. A. et al. An optimized library for reference-based deconvolution of whole-blood biospecimens assayed using the Illumina HumanMethylationEPIC BeadArray. Genome biology 19, 64; 10.1186/s13059-018-1448-7. (2018).

21. Ritchie, M. E. et al. limma powers differential expression analyses for RNA-sequencing and microarray studies. Nucleic acids research 43, e47; 10.1093/nar/gkv007 (2015).

22. Peters, T. J. et al. De novo identification of differentially methylated regions in the human genome. Epigenetics \& chromatin 8, 6; 10.1186/1756-8935-8-6 (2015).

23. Cavalcante, R. G. \& Sartor, M. A. annotatr: genomic regions in context. Bioinformatics (Oxford, England) 33, 2381-2383; 10.1093/bioinformatics/btx 183 (2017).

24. Conway, J. R., Lex, A. \& Gehlenborg, N. UpSetR: an R package for the visualization of intersecting sets and their properties. Bioinformatics (Oxford, England) 33, 2938-2940; 10.1093/bioinformatics/btx364 (2017).

25. Pelegí-Sisó, D., Prado, P. de, Ronkainen, J., Bustamante, M. \& González, J. R. methylclock: a Bioconductor package to estimate DNA methylation age. Bioinformatics (Oxford, England) 37, 1759-1760; 10.1093/bioinformatics/btaa825 (2021).

26. Yu, G., Wang, L.-G., Han, Y. \& He, Q.-Y. clusterProfiler: an R package for comparing biological themes among gene clusters. Omics : a journal of integrative biology 16, 284-287; 10.1089/omi.2011.0118 (2012).

27. Kirsten, H. et al. Dissecting the genetics of the human transcriptome identifies novel traitrelated trans-eQTLs and corroborates the regulatory relevance of non-protein coding loci†. Human molecular genetics 24, 4746-4763; 10.1093/hmg/ddv194 (2015).

28. Schmid, R. et al. Comparison of normalization methods for Illumina BeadChip HumanHT-12 v3. BMC genomics 11, 349; 10.1186/1471-2164-11-349 (2010).

29. Du, P., Kibbe, W. A. \& Lin, S. M. lumi: a pipeline for processing Illumina microarray. Bioinformatics (Oxford, England) 24, 1547-1548; 10.1093/bioinformatics/btn224 (2008).

30. Johnson, W. E., Li, C. \& Rabinovic, A. Adjusting batch effects in microarray expression data using empirical Bayes methods. Biostatistics (Oxford, England) 8, 118-127; 10.1093/biostatistics/kxj037 (2007).

31. QIAGEN Inc. IPA - ingenuity pathway analysis. Available at https://www.qiagenbioinformatics.com/products/ingenuitypathway-analysis. 
32. Cohen Freue, G. V. et al. MDQC: a new quality assessment method for microarrays based on quality control reports. Bioinformatics (Oxford, England) 23, 3162-3169; 10.1093/bioinformatics/btm487 (2007).

33. Thermo Fisher Scientific. Axiom Genotyping Solution Data Analysis Guide (2017).

34. Pott, J. et al. Genome-wide meta-analysis identifies novel loci of plaque burden in carotid artery. Atherosclerosis 259, 32-40; 10.1016/j.atherosclerosis.2017.02.018 (2017).

35. König, I. R., Loley, C., Erdmann, J. \& Ziegler, A. How to include chromosome X in your genome-wide association study. Genetic epidemiology 38, 97-103; 10.1002/gepi.21782 (2014).

36. Auton, A. et al. A global reference for human genetic variation. Nature 526, 68-74; 10.1038/nature15393 (2015).

37. Delaneau, O., Howie, B., Cox, A. J., Zagury, J.-F. \& Marchini, J. Haplotype estimation using sequencing reads. American journal of human genetics 93, 687-696; 10.1016/j.ajhg.2013.09.002 (2013).

38. Howie, B. N., Donnelly, P. \& Marchini, J. A flexible and accurate genotype imputation method for the next generation of genome-wide association studies. PLoS genetics $\mathbf{5}$, e1000529; 10.1371/journal.pgen.1000529 (2009).

39. Shabalin, A. A. Matrix eQTL: ultra fast eQTL analysis via large matrix operations. Bioinformatics (Oxford, England) 28, 1353-1358; 10.1093/bioinformatics/bts 163 (2012).

40. R Core Team (2021). R: A language and environment for statistical computing. Available at https://www.R-project.org/.

41. Buniello, A. et al. The NHGRI-EBI GWAS Catalog of published genome-wide association studies, targeted arrays and summary statistics 2019 . Nucleic acids research 47, D1005D1012; 10.1093/nar/gky1120 (2019).

42. Zhang, Y. et al. F2RL3 methylation in blood DNA is a strong predictor of mortality. International journal of epidemiology 43, 1215-1225; 10.1093/ije/dyu006 (2014).

43. Barcelona, V. et al. Novel DNA methylation sites associated with cigarette smoking among African Americans. Epigenetics 14, 383-391; 10.1080/15592294.2019.1588683 (2019).

44. Tsai, P.-C. et al. Smoking induces coordinated DNA methylation and gene expression changes in adipose tissue with consequences for metabolic health. Clinical epigenetics $\mathbf{1 0}$, 126; 10.1186/s 13148-018-0558-0 (2018).

45. Do, W. L. et al. Examining the association between adiposity and DNA methylation: A systematic review and meta-analysis. Obesity reviews : an official journal of the International Association for the Study of Obesity, e13319; 10.1111/obr.13319 (2021).

46. Quach, A. et al. Epigenetic clock analysis of diet, exercise, education, and lifestyle factors. Aging 9, 419-446; 10.18632/aging.101168 (2017).

47. Godfrey, K. M. et al. Epigenetic gene promoter methylation at birth is associated with child's later adiposity. Diabetes 60, 1528-1534; 10.2337/db10-0979 (2011). 
medRxiv preprint doi: https://doi.org/10.1101/2021.12.16.21267895; this version posted December 17, 2021. The copyright holder for this preprint (which was not certified by peer review) is the author/funder, who has granted medRxiv a license to display the preprint in perpetuity.

It is made available under a CC-BY-NC-ND 4.0 International license .

815

816

817

818

819

820

821

822

823

824

825

826

827

828

829

830

831

832

833

834

48. Bauer, M. et al. Tobacco smoking differently influences cell types of the innate and adaptive immune system-indications from $\mathrm{CpG}$ site methylation. Clinical epigenetics 7, 83; 10.1186/s13148-016-0249-7 (2015).

49. Breitling, L. P., Salzmann, K., Rothenbacher, D., Burwinkel, B. \& Brenner, H. Smoking, F2RL3 methylation, and prognosis in stable coronary heart disease. European heart journal 33, 2841-2848; 10.1093/eurheartj/ehs091 (2012).

50. Alhamdow, A. et al. DNA methylation of the cancer-related genes F2RL3 and AHRR is associated with occupational exposure to polycyclic aromatic hydrocarbons. Carcinogenesis 39, 869-878; 10.1093/carcin/bgy059 (2018).

51. Karabegović, I. et al. Epigenome-wide association meta-analysis of DNA methylation with coffee and tea consumption. Nature communications 12, 2830; 10.1038/s41467-021-22752-6 (2021).

52. Redonnet, A. et al. Synergic effect of vitamin A and high-fat diet in adipose tissue development and nuclear receptor expression in young rats. The British journal of nutrition 100, 722-730; 10.1017/S0007114508967568 (2008).

53. Lee, P. H., Macfarlane, D. J., Lam, T. H. \& Stewart, S. M. Validity of the International Physical Activity Questionnaire Short Form (IPAQ-SF): a systematic review. The international journal of behavioral nutrition and physical activity 8, 115; 10.1186/14795868-8-115 (2011). 


\section{Figure 1}

medRxiv preprint doi: https://doi org/10.1101/2021.12.16.21267895; this version posted December 17,2021. The copyright holder for this

a) preprint (which was not certified by peer review) is the auther)funder, who has granted medRxiv a license to display the preprint in perpetuity. It is made available under a CC-BY-NC-ND 4.0 International license .

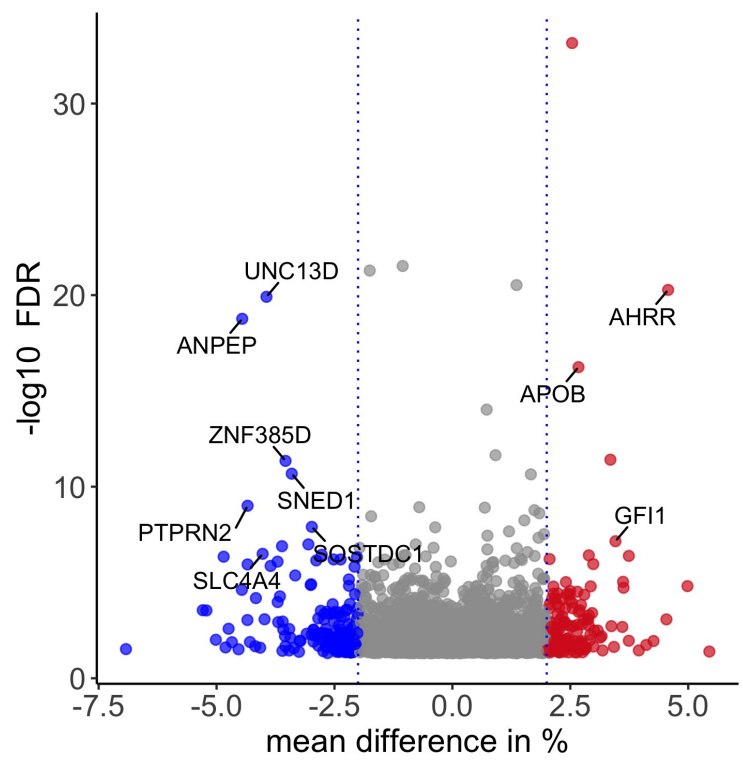

Glutamatergic synapse Transcriptional misregulation in cancer Signaling pathways regulating pluripotency of stem cells Non-small cell lung cancer Hepatocellular carcinoma Growth hormone synthesis, secretion and action Gastric cancer Axon guidance Rap1 signaling pathway

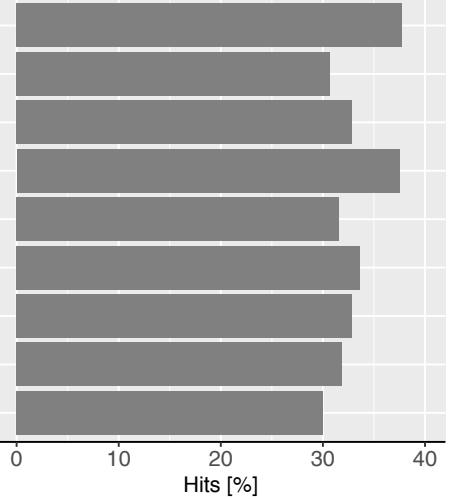

b)

d)

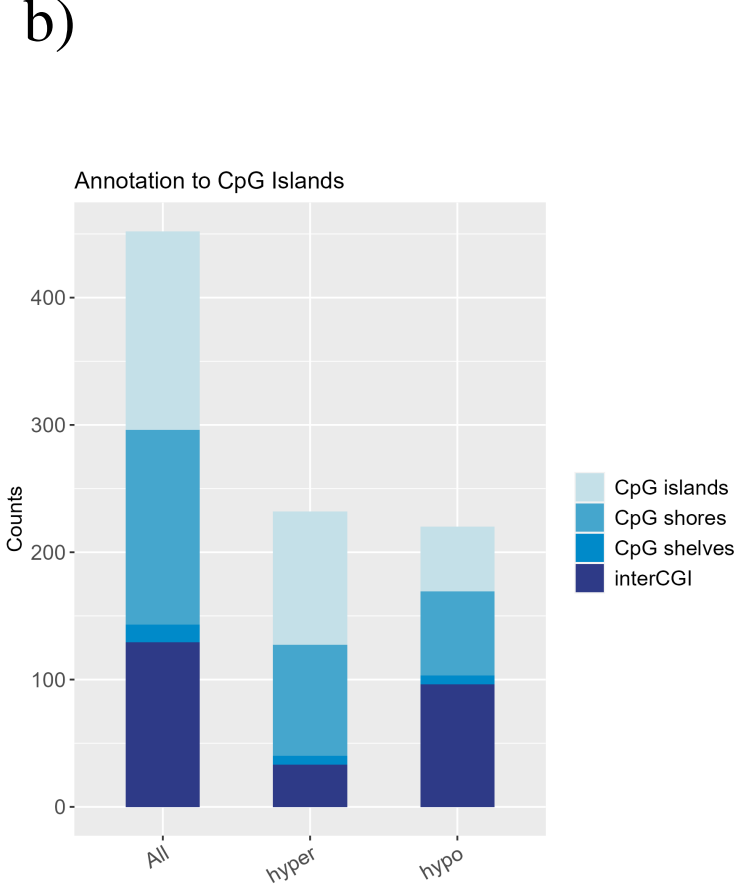

Annotation to gene regions

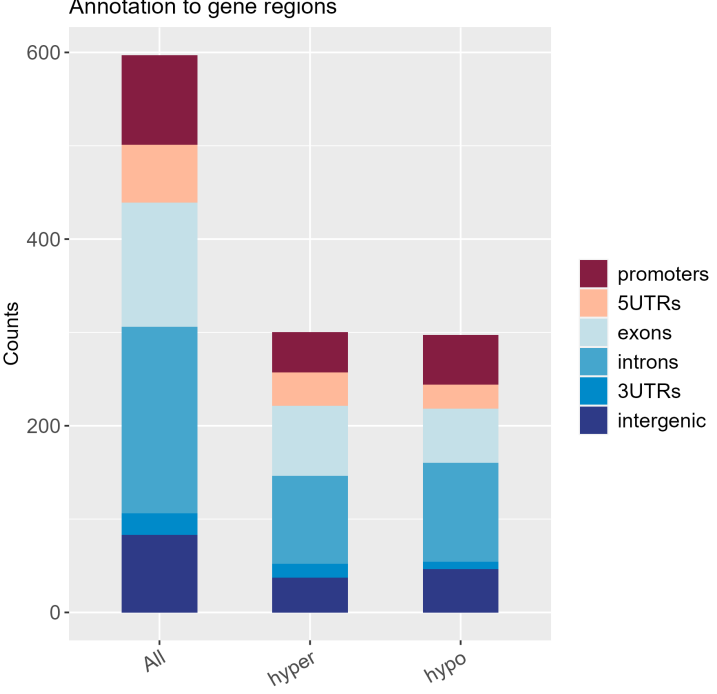

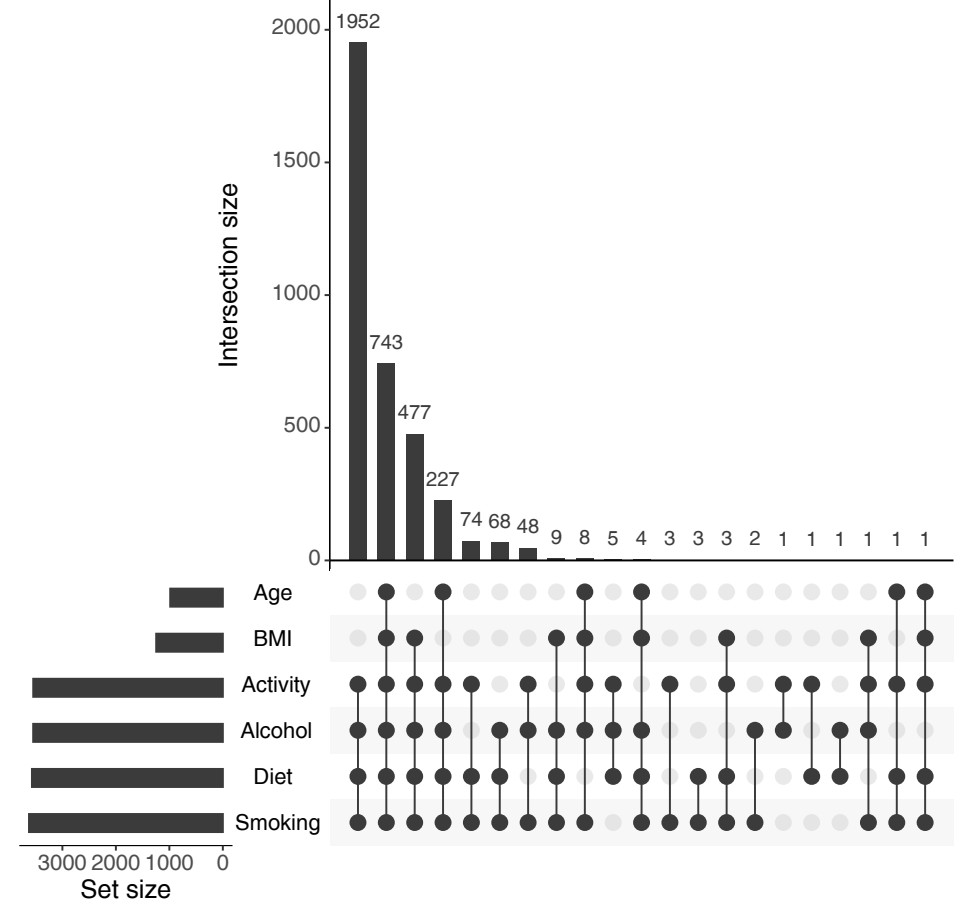


Figure 2

a) medRxiv preprint doi: https://doi.org/10.1101/2021.12.16.2/1267895; this version posted December 17, 2021. The copyright holder for this
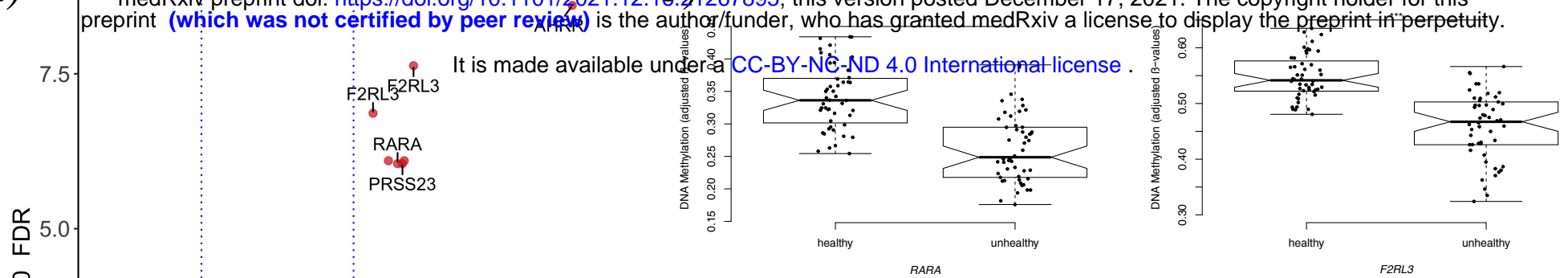

$\frac{}{8}$
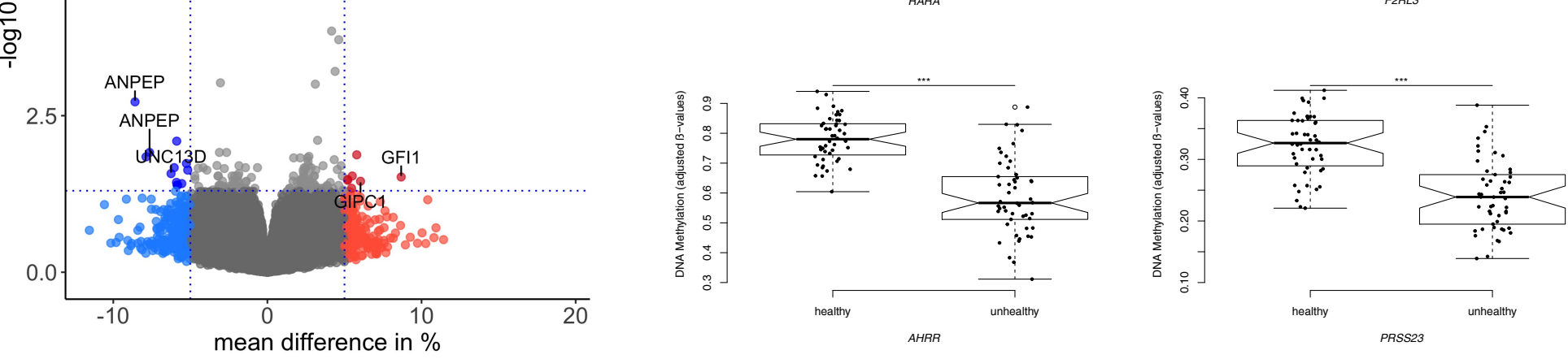

c)

d)
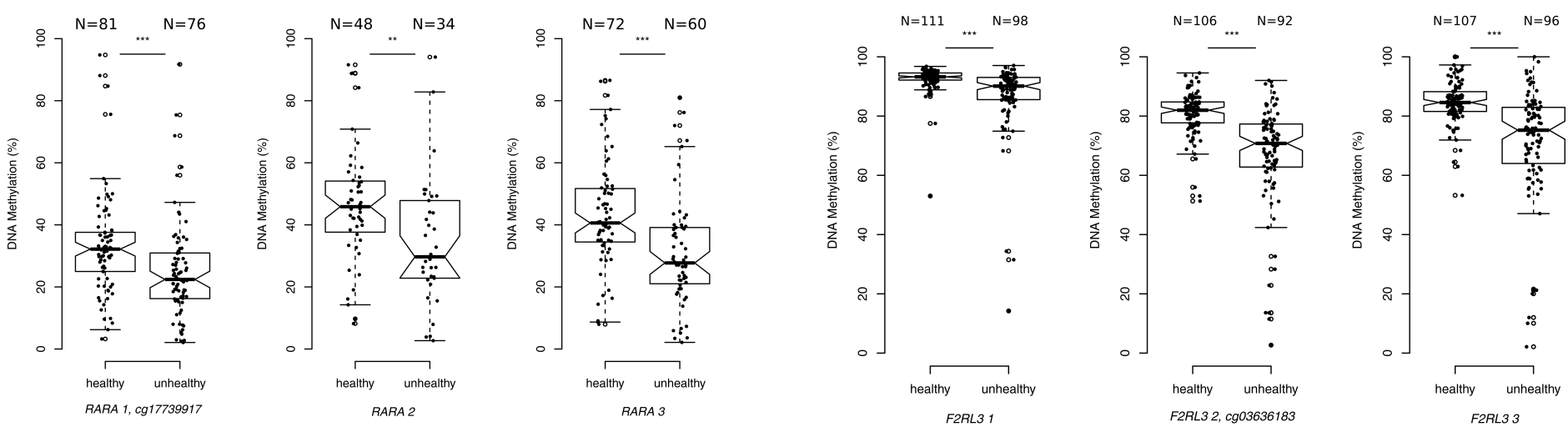

e)
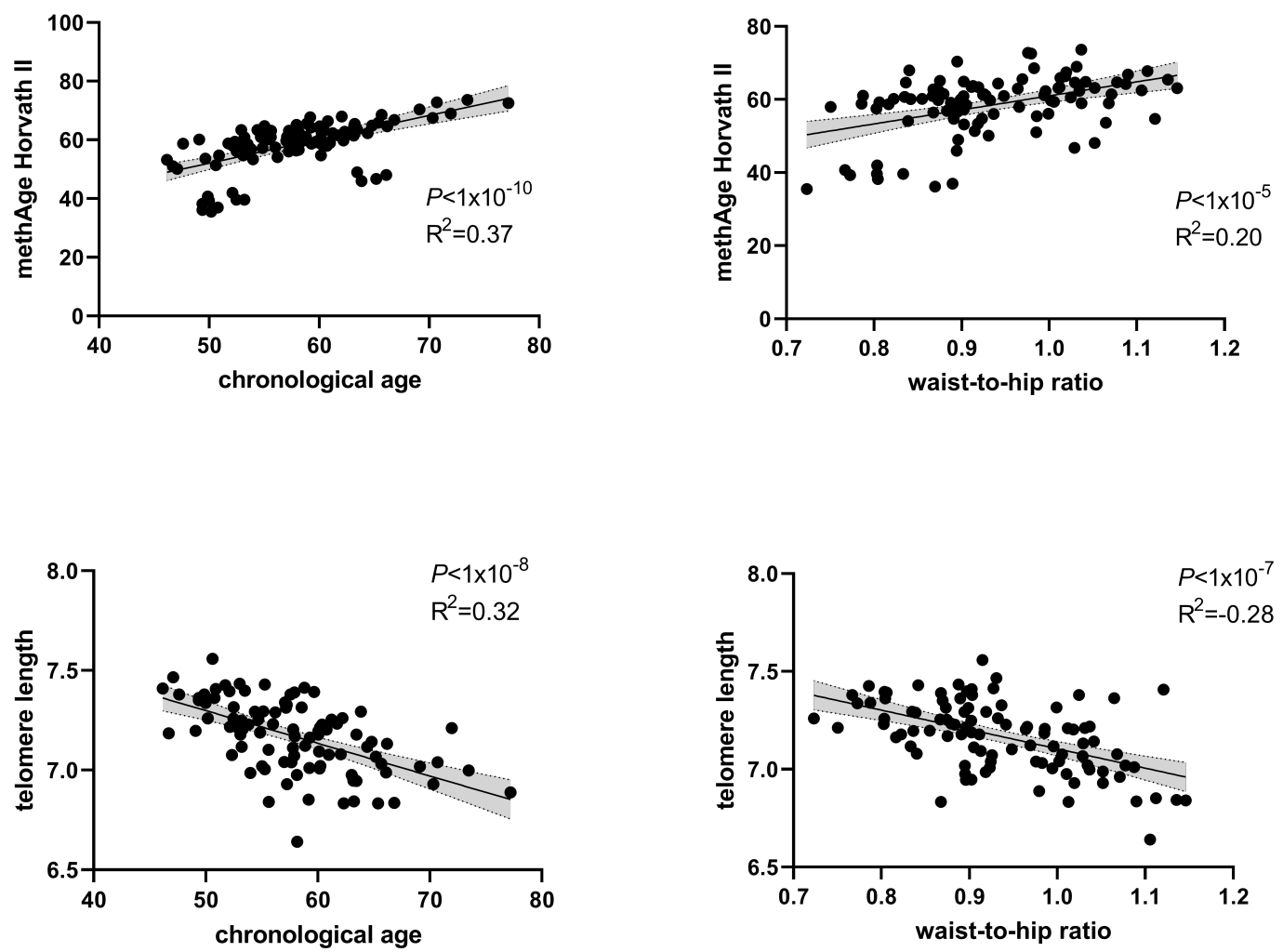
$\underline{\text { Table } 1 \text {-Study characteristics }}$

\begin{tabular}{|c|c|c|c|c|}
\hline & LIFE cohort & Healthy Lifstyle (LS $\leq 5^{\text {th }}$ pct.) & Unhealthy Lifestyle (LS $\geq 95^{\text {th }}$ pct.) & $P$-values (LS 5th vs. 95th pct.) \\
\hline N (total number) & 4107 & 216 & 207 & \\
\hline Gender ( $N$ : female/male) & $2109 / 1998$ & $160 / 56$ & $66 / 141$ & \\
\hline Age (years) & $55.9 \pm 12.8$ & $60.14 \pm 12.76$ & $54.03 \pm 10.47$ & $<0.001$ \\
\hline BMI $\left(\mathrm{kg} / \mathrm{m}^{2}\right)$ & $27.03 \pm 4.65$ & $27.11 \pm 4.74$ & $27.31 \pm 4.69$ & \\
\hline BMI category ( $N$ : lean/obese/overweight) & $1488 / 1659 / 940$ & $73 / 95 / 48$ & $67 / 93 / 46$ & \\
\hline Waist circumference $(\mathrm{cm})$ & $95.71 \pm 13.02$ & $93.46 \pm 12.18$ & $99.52 \pm 13.59$ & $<0.001$ \\
\hline Waist-to-Hip Ratio & $0.93 \pm 0.09$ & $0.9 \pm 0.08$ & $0.97 \pm 0.08$ & $<0.001$ \\
\hline Fasting plasma glucose (mmol/l) & $5.56 \pm 0.79$ & $5.63 \pm 0.79$ & $5.61 \pm 0.72$ & \\
\hline Fasting plasma insulin (pmol/l) & $63.33 \pm 42.82$ & $58.53 \pm 36.99$ & $66.66 \pm 43.77$ & \\
\hline Plasma Low Density Lipoprotein (mmol/l) & $3.5 \pm 0.95$ & $3.5 \pm 0.93$ & $3.63 \pm 0.97$ & \\
\hline Plasma High Density Lipoprotein (mmol/l) & $1.62 \pm 0.46$ & $1.79 \pm 0.45$ & $1.44 \pm 0.42$ & $<0.001$ \\
\hline Plasma Apolipoprotein A1 (g/l) & $1.67 \pm 0.3$ & $1.76 \pm 0.27$ & $1.6 \pm 0.3$ & $<0.001$ \\
\hline Plasma Triglycerides $(\mathrm{mmol} / \mathrm{l})$ & $1.38 \pm 1.1$ & $1.17 \pm 0.58$ & $1.68 \pm 1.03$ & $<0.001$ \\
\hline Diet Score & $12.39 \pm 3.22$ & $8.69 \pm 1.94$ & $15.39 \pm 3.08$ & $<0.001$ \\
\hline Physical activity Score & $7.55 \pm 6.47$ & $0.58 \pm 1.6$ & $17.25 \pm 3.8$ & $<0.001$ \\
\hline Smoking Score & $5.91 \pm 6.70$ & $0.09 \pm 0.68$ & $16.81 \pm 3.58$ & $<0.001$ \\
\hline Alcohol Score & $1.34 \pm 2.22$ & $0.09 \pm 0.68$ & $2.97 \pm 2.46$ & $<0.001$ \\
\hline LS & $27.19 \pm 11.02$ & $9.45 \pm 1.54$ & $52.42 \pm 4.07$ & $<0.001$ \\
\hline
\end{tabular}


Table 2 - Top lifestyle specific Differentially Methylated Regions (DMRs)

\begin{tabular}{|c|c|c|c|c|c|c|c|c|}
\hline & Chromosome & Start & End & Number CpGs & Min smoothed FDR & Max difference & Mean difference & UCSC RefGene name \\
\hline \multirow{15}{*}{ 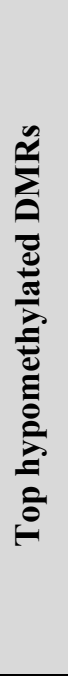 } & $\operatorname{chr} 5$ & 179740743 & 179741120 & 4 & 0.029977938 & -0.115525323 & -0.069213857 & GFPT2 \\
\hline & chr3 & 53700141 & 53700263 & 3 & 0.000280372 & -0.058166831 & -0.052935571 & $C A C N A 1 D$ \\
\hline & chr10 & 130726406 & 130726701 & 3 & 0.000287833 & -0.066141442 & -0.052150296 & $N A$ \\
\hline & $\operatorname{chr} 16$ & 55866757 & 55867072 & 4 & 0.009779257 & -0.084082934 & -0.050156174 & CES1 \\
\hline & chr20 & 55835831 & 55836676 & 4 & $4.50739 \mathrm{E}-07$ & -0.063006443 & -0.048500957 & $B M P 7$ \\
\hline & chr4 & 169770092 & 169770406 & 3 & 0.024472101 & -0.051377777 & -0.04809308 & PALLD \\
\hline & chr1 & 58898552 & 58898793 & 3 & 0.002601555 & -0.062311841 & -0.047451925 & $D A B 1$ \\
\hline & $\operatorname{chr} 10$ & \begin{tabular}{|l|}
128810484 \\
\end{tabular} & \begin{tabular}{|l|}
128810904 \\
\end{tabular} & 3 & 0.013077709 & -0.057183472 & -0.046745655 & DOCK1 \\
\hline & chr20 & 61590751 & 61591066 & 3 & 0.03067276 & -0.048455427 & -0.045342149 & SLC17A9 \\
\hline & chr3 & \begin{tabular}{|l|}
29377160 \\
\end{tabular} & \begin{tabular}{|l|}
29377980 \\
\end{tabular} & 3 & $2.4182 \mathrm{E}-05$ & -0.072396235 & -0.044645175 & $R B M S 3$ \\
\hline & $\operatorname{chr} 15$ & 90345999 & 90346923 & 5 & $1.72483 \mathrm{E}-19$ & -0.08590341 & -0.044563113 & ANPEP \\
\hline & chr11 & 132662455 & 132662963 & 4 & 0.000910498 & -0.05680831 & -0.04346194 & $O P C M L$ \\
\hline & chr6 & 170557102 & 170558102 & 6 & $1.1415 \mathrm{E}-06$ & -0.072104452 & -0.043424206 & $N A$ \\
\hline & chr7 & 157405965 & 157406737 & 6 & $9.89334 \mathrm{E}-10$ & -0.058499659 & -0.043422181 & PTPRN2 \\
\hline & chr10 & 134332277 & 134332442 & 3 & 0.012827793 & -0.051679361 & -0.042922001 & $N A$ \\
\hline \multirow{15}{*}{ 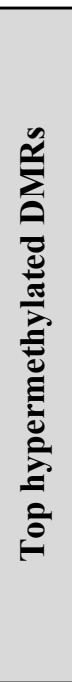 } & chr8 & 637468 & 637909 & 3 & 0.040227828 & 0.096584379 & 0.054484963 & ERICHI \\
\hline & chr10 & 90984672 & 90985062 & 3 & $1.55 \mathrm{E}-05$ & 0.056039743 & 0.049841417 & $L I P A$ \\
\hline & chr6 & 29648161 & 29649084 & 21 & $1.27008 \mathrm{E}-08$ & 0.070683917 & 0.046436136 & ZFP57 \\
\hline & chr5 & 373378 & 374252 & 4 & $5.36 \mathrm{E}-21$ & 0.193803612 & 0.045739382 & AHRR \\
\hline & chr2 & \begin{tabular}{|l|}
113992694 \\
\end{tabular} & \begin{tabular}{|l|}
113994035 \\
\end{tabular} & 9 & $8.42 \mathrm{E}-04$ & 0.061941445 & 0.045375298 & $P A X 8 ; P A X 8-A S 1$ \\
\hline & chr6 & 291687 & 292823 & 9 & 0.011323863 & 0.053011157 & 0.042649384 & DUSP22 \\
\hline & $\operatorname{chr} 10$ & 3282585 & 3282783 & 3 & 0.018194186 & 0.042427159 & 0.041105344 & $N A$ \\
\hline & chr11 & 6592066 & 6592585 & 4 & 0.035060323 & 0.04489839 & 0.039528971 & DNHD1 \\
\hline & chr17 & 45949677 & 45949878 & 5 & 4.08384E-07 & 0.050310751 & 0.037408698 & $N A$ \\
\hline & chr20 & 17595355 & 17595472 & 3 & 0.010978827 & 0.058269466 & 0.037403949 & $R R B P 1$ \\
\hline & chr16 & 85362963 & 85363209 & 4 & $1.88794 \mathrm{E}-05$ & 0.050747768 & 0.036293171 & $N A$ \\
\hline & $\operatorname{chr} 5$ & 171056823 & 171057575 & 7 & $9.23649 \mathrm{E}-06$ & 0.042779917 & 0.036184758 & $N A$ \\
\hline & chr6 & 33047185 & 33049505 & 21 & $1.19801 \mathrm{E}-13$ & 0.081605453 & 0.036098647 & $H L A-D P A 1 ; H L A-D P B 1$ \\
\hline & chr1 & 112161618 & 112162084 & 4 & 0.002088251 & 0.065164708 & 0.03602836 & $R A P 1 A$ \\
\hline & chr1 & 92946700 & 92947961 & 6 & $7.03132 \mathrm{E}-08$ & 0.086788359 & 0.034577075 & $G F I 1$ \\
\hline
\end{tabular}


Table 3 - Top lifestyle specific Differentially Methylated Positions (DMPs)

\begin{tabular}{|c|c|c|c|c|c|c|c|c|c|c|c|}
\hline & Log fold change & Average Expression & t-value & $P$-value & Adj. $P$-value & B-value & Chromosom & Position & Strand & CpG-Name & UCSC RefGene name \\
\hline \multirow{10}{*}{ 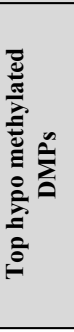 } & -0.08590341 & 0.611707079 & -5.998155947 & $3.32 \mathrm{E}-08$ & 0.001904 & 7.711471263 & chr15 & 90345999 & - & $\operatorname{cg} 06344992$ & ANPEP \\
\hline & -0.078774849 & 0.42479436 & -5.431011449 & $4.05 \mathrm{E}-07$ & 0.014379921 & 5.260694048 & chr3 & 22412124 & + & $\operatorname{cg} 05529343$ & - \\
\hline & -0.076464321 & 0.588248951 & -5.523118419 & $2.72 \mathrm{E}-07$ & 0.012223739 & 5.650244644 & chr15 & 90346089 & - & cg02008229 & $A N P E P$ \\
\hline & -0.062518007 & 0.406780726 & -5.085850571 & $1.75 \mathrm{E}-06$ & 0.02663562 & 3.833220233 & chr17 & 73824396 & - & $\operatorname{cg} 07010633$ & $U N C 13 D$ \\
\hline & -0.060472705 & 0.627160734 & -5.216582762 & $1.01 \mathrm{E}-06$ & 0.021387415 & 4.36768357 & chr16 & 70838524 & + & $\operatorname{cg} 16450432$ & - \\
\hline & -0.058989842 & 0.656861761 & -4.879931872 & $4.10 \mathrm{E}-06$ & 0.036747315 & 3.007614002 & $\operatorname{chr} 17$ & 73824620 & - & cg23891399 & $U N C 13 D$ \\
\hline & -0.058856163 & 0.721651694 & -5.641262144 & $1.62 \mathrm{E}-07$ & 0.008069468 & 6.154917623 & chr15 & 90346094 & - & cg23432008 & ANPEP \\
\hline & -0.05865088 & 0.2639215 & -4.825085 & $5.12 \mathrm{E}-06$ & 0.04057961 & 2.791195 & chr2 & 241976080 & - & $\operatorname{cg} 26718213$ & SNEDI \\
\hline & -0.058146578 & 0.501398588 & -4.822217419 & $5.18 \mathrm{E}-06$ & 0.040621906 & 2.779921567 & chr1 & 14928945 & - & $\operatorname{cg} 08538034$ & KIAA1026 \\
\hline & -0.055549608 & 0.643279716 & -4.851889553 & $4.59 \mathrm{E}-06$ & 0.038439331 & 2.896775344 & chr4 & 72119734 & + & cg13530673 & SLC4A4 \\
\hline \multirow{10}{*}{ 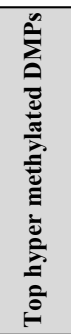 } & 0.193803612 & 0.681740677 & 9.330229512 & $3.34089 \mathrm{E}-15$ & $2.48875 \mathrm{E}-09$ & 23.67151784 & chr5 & 373378 & + & $\operatorname{cg} 05575921$ & $A H R R$ \\
\hline & 0.089458236 & 0.502052675 & 8.742631823 & $6.28569 \mathrm{E}-14$ & $2.34122 \mathrm{E}-08$ & 20.75139172 & chr19 & 17000585 & - & cg03636183 & $F 2 R L 3$ \\
\hline & 0.086788359 & 0.554523661 & 4.995475984 & $2.54941 \mathrm{E}-06$ & 0.030145161 & 3.468373598 & chr1 & 92947588 & + & cg09935388 & GFII \\
\hline & 0.083336995 & 0.62903076 & 7.843482601 & $5.36488 \mathrm{E}-12$ & $7.99298 \mathrm{E}-07$ & 16.33498038 & chr2 & 233284661 & - & cg21566642 & - \\
\hline & 0.082181848 & 0.281667406 & 7.78234353 & $7.23702 \mathrm{E}-12$ & $8.90834 \mathrm{E}-07$ & 16.03813512 & chr11 & 86513429 & + & cg14391737 & PRSS23 \\
\hline & 0.078959254 & 0.30069194 & 7.752577018 & $8.37097 \mathrm{E}-12$ & $8.90834 \mathrm{E}-07$ & 15.8938087 & chr17 & 38477572 & - & cg17739917 & RARA \\
\hline & 0.07293225 & 0.467577109 & 7.867015889 & $4.78042 \mathrm{E}-12$ & $7.99298 \mathrm{E}-07$ & 16.44938219 & chr2 & 233284934 & - & cg01940273 & - \\
\hline & 0.062807746 & 0.693318329 & 8.305152712 & $5.51963 \mathrm{E}-13$ & $1.37059 \mathrm{E}-07$ & 18.5921592 & chr19 & 16998668 & + & cg21911711 & $F 2 R L 3$ \\
\hline & 0.060416895 & 0.182824945 & 4.908439221 & $3.64634 \mathrm{E}-06$ & 0.035276471 & 3.120689146 & $\operatorname{chr} 19$ & 14591033 & + & cg20742389 & GIPCI \\
\hline & 0.057960459 & 0.560933206 & 5.47153733 & $3.40315 \mathrm{E}-07$ & 0.013342801 & 5.431662125 & chr14 & 77248049 & + & $\operatorname{cg} 10387007$ & VASHI \\
\hline
\end{tabular}




\section{Supplemental Material 1}

\section{Lifestyle sub-scores}

Briefly, the diet score was based on the German FFQ where all participants were asked about their frequency in consumption of 34 different food groups and 13 beverages during the last year ${ }^{1}$. Among them we considered six food groups as favorable (e.g. fish, vegetables, and whole grain products) and eight as unfavorable (e.g. pan-fried potato products, meat and cold cuts, fast-food, and instant products), after testing their correlation to BMI. All Participants could choose from several categories: eating each food group a) several times per day, b) each day or almost each day, c) several times per week, d) once per week, e) two or three times per month, f) once or less a month, g) or rather never ${ }^{2}$ (Supplemental Table 1). For the diet score, frequently consumed unfavorable foods counted high, whereas frequently consumed favorable foods counted low (Supplemental Table 1). In line with this, a high diet score correspond to an unfavorable eating pattern as previously described ${ }^{3}$.

For the physical activity score we used the SF-IPAQ ${ }^{4}$ and included the absolute activity measured as Metabolic Equivalent of Task-minutes per week (MET-min/week) and the categorical physical activity level as a) low, b) moderate, and c) intensive, as results of the questionnaire evaluation algorithm ${ }^{1,5}$. We scored the activity levels from intense to moderate to low (0-5-10) and used quartiles from the entire cohort distribution of MET-minutes/week for the absolute activity scoring as shown in Supplemental Table 1. In total, the physical activity score was calculated as sum of absolute and categorical activity levels.

For smoking behavior, we used the available data from the LIFE-Adult cohort regarding the current smoking status (non-smoker, previous smoker and current smoker) as well as the number of pack years (number of years with an average of one cigarette pack per day). Zero points were assigned to non-smoking, five points to previous smoking, and the maximum of 10 points to current smokers. For converting the number of pack years into scoring points, we used again the classification into quartiles as shown in Supplemental Table 1. The sum of the two scores provided the final smoking score.

Finally, based on the recommendation of the German nutrition society (DGE) we set thresholds for alcohol consumption to create the alcohol score at ten grams per day for females and 20 grams for males. Subjects below or equaling these cut offs scored 0 and those above the thresholds were assigned 5 points.

\section{References}

1. Loeffler, M. et al. The LIFE-Adult-Study: objectives and design of a population-based cohort study with 10,000 deeply phenotyped adults in Germany. BMC public health 15, 691; 10.1186/s12889-0151983-z (2015).

2. Kroke, A. et al. Validation of a self-administered food-frequency questionnaire administered in the European Prospective Investigation into Cancer and Nutrition (EPIC) Study: comparison of energy, protein, and macronutrient intakes estimated with the doubly labeled water, urinary nitrogen, and repeated 24-h dietary recall methods. Am J Clin Nutr 70, 439-447; 10.1093/ajcn/70.4.439 (1999).

3. Nettleton, J. A. et al. Meta-analysis investigating associations between healthy diet and fasting glucose and insulin levels and modification by loci associated with glucose homeostasis in data from 15 cohorts. American journal of epidemiology 177, 103-115; 10.1093/aje/kws297 (2013). 
medRxiv preprint doi: https://doi.org/10.1101/2021.12.16.21267895; this version posted December 17, 2021. The copyright holder for this preprint (which was not certified by peer review) is the author/funder, who has granted medRxiv a license to display the preprint in perpetuity.

It is made available under a CC-BY-NC-ND 4.0 International license .

4. Craig, C. L. et al. International physical activity questionnaire: 12 -country reliability and validity. Medicine and science in sports and exercise 35, 1381-1395; 10.1249/01.MSS.0000078924.61453.FB (2003).

5. The IPAQ group. The IPAQ. Available at https://sites.google.com/site/theipaq/. 
Supplemental Figure 1

medRxiv preprint doi: https: Goi.org/10.1101/2021.12.16.21267895; this version posted December 17, 2021. The copyright holder for this preprint (which was not certified by peer review) is the author/funder, who has granted medRxiv a license to display the preprint in perpetuity.

a)

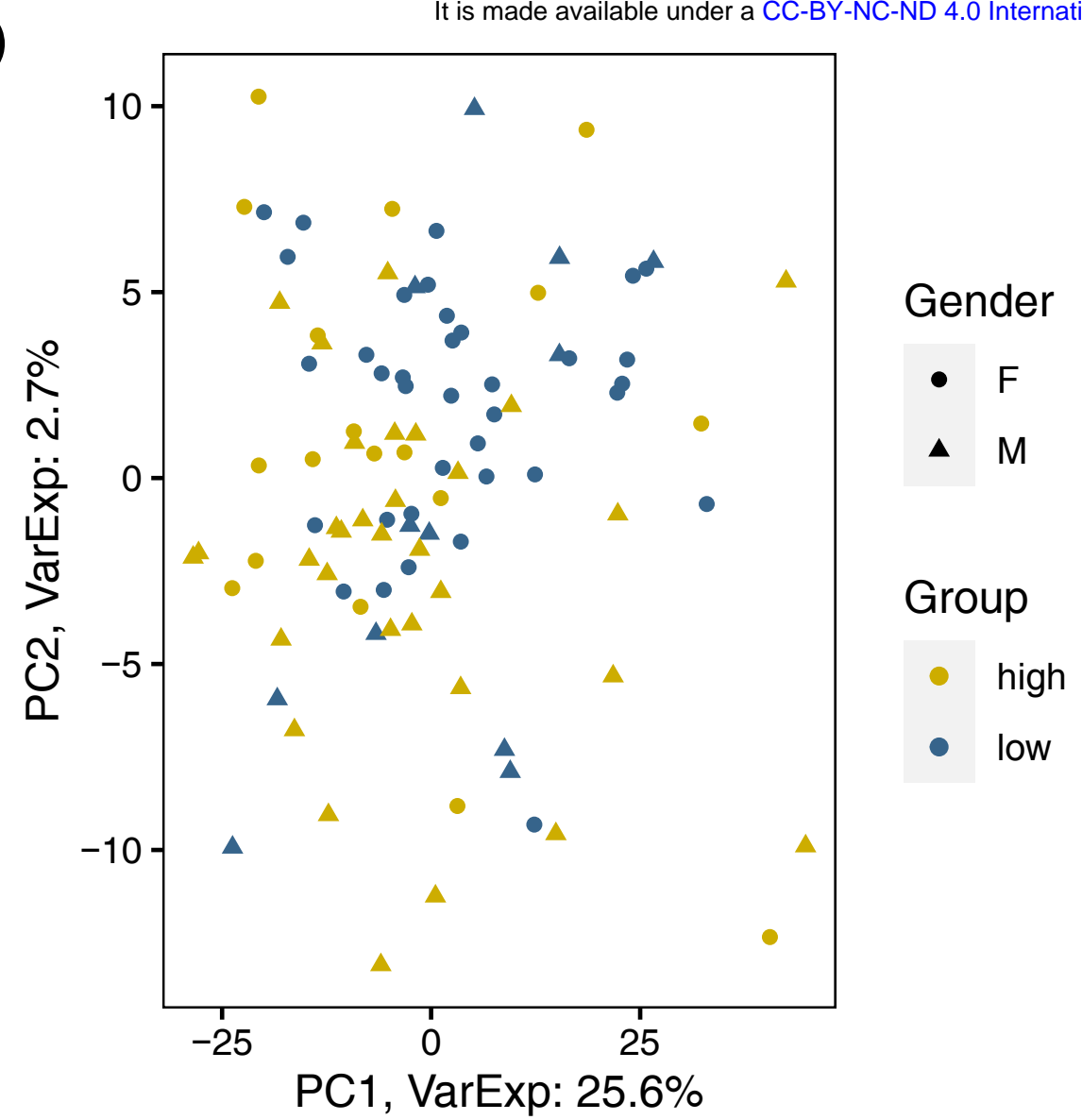

b) It is made available under a CC-BY-NC-ND 4.0 International license .

\section{Estimation Plot}

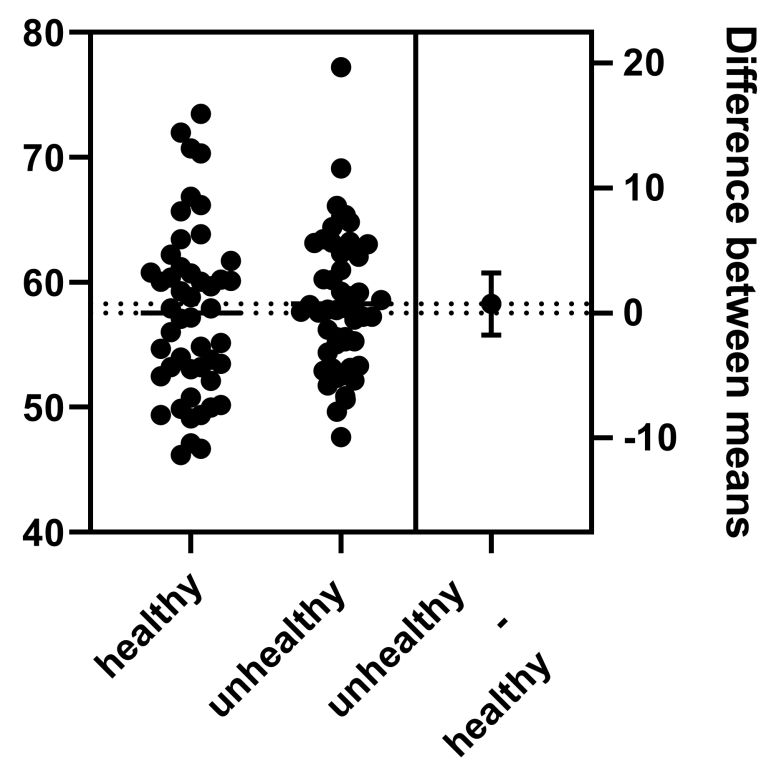




\section{Supplemental Figure 2}

medRxiv preprint doi: https:/0oi.org/10.1101/2021.12 16.21267895; this version posted December 17, 2021. The copyright holder for this preprint (which was not certified by peer review) is the author/funder, who has granted medRxiv a license to display the preprint in perpetuity.

a)

It is made available under a CC-BY-NC-ND 4.0 International license .
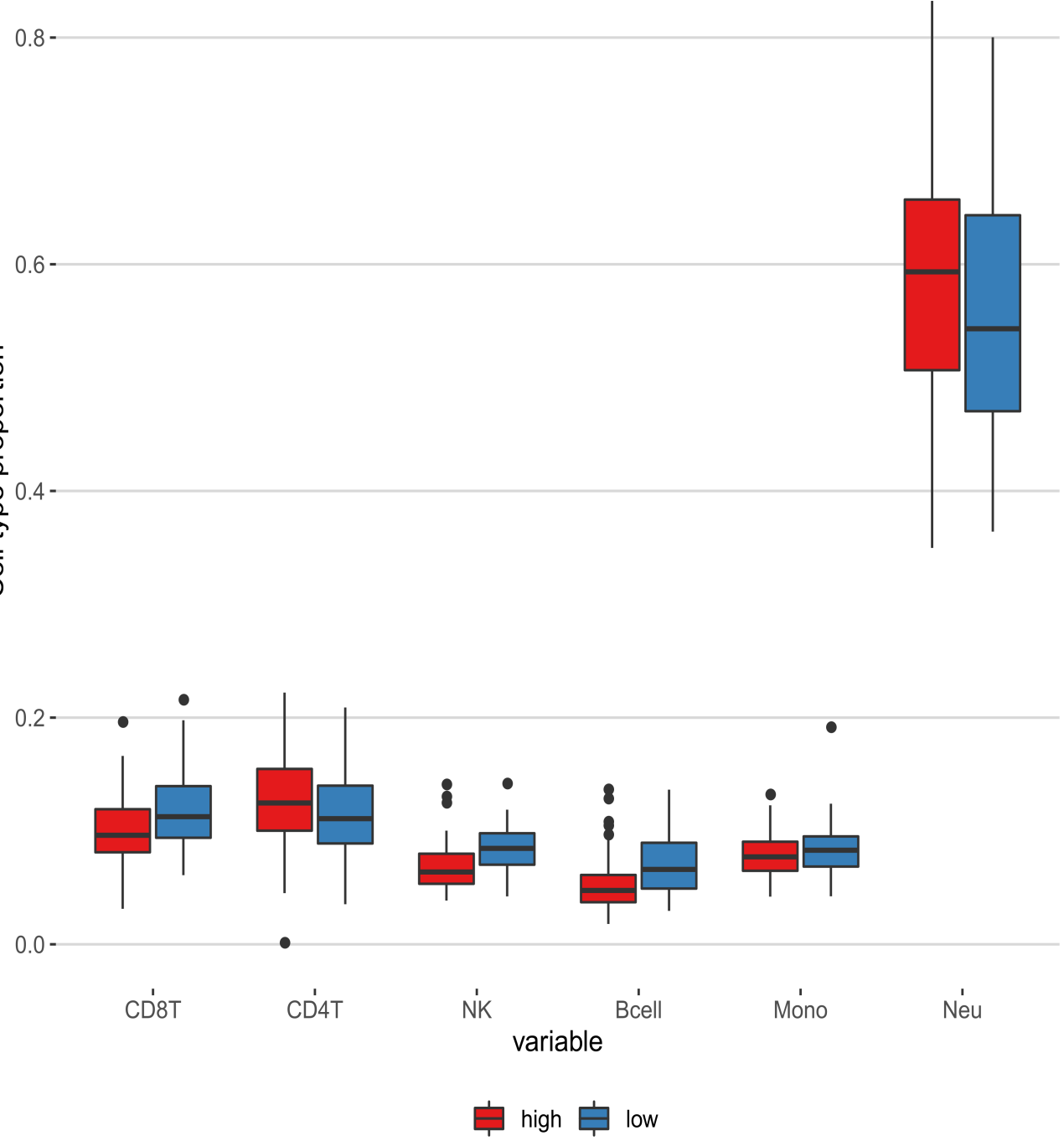

b)

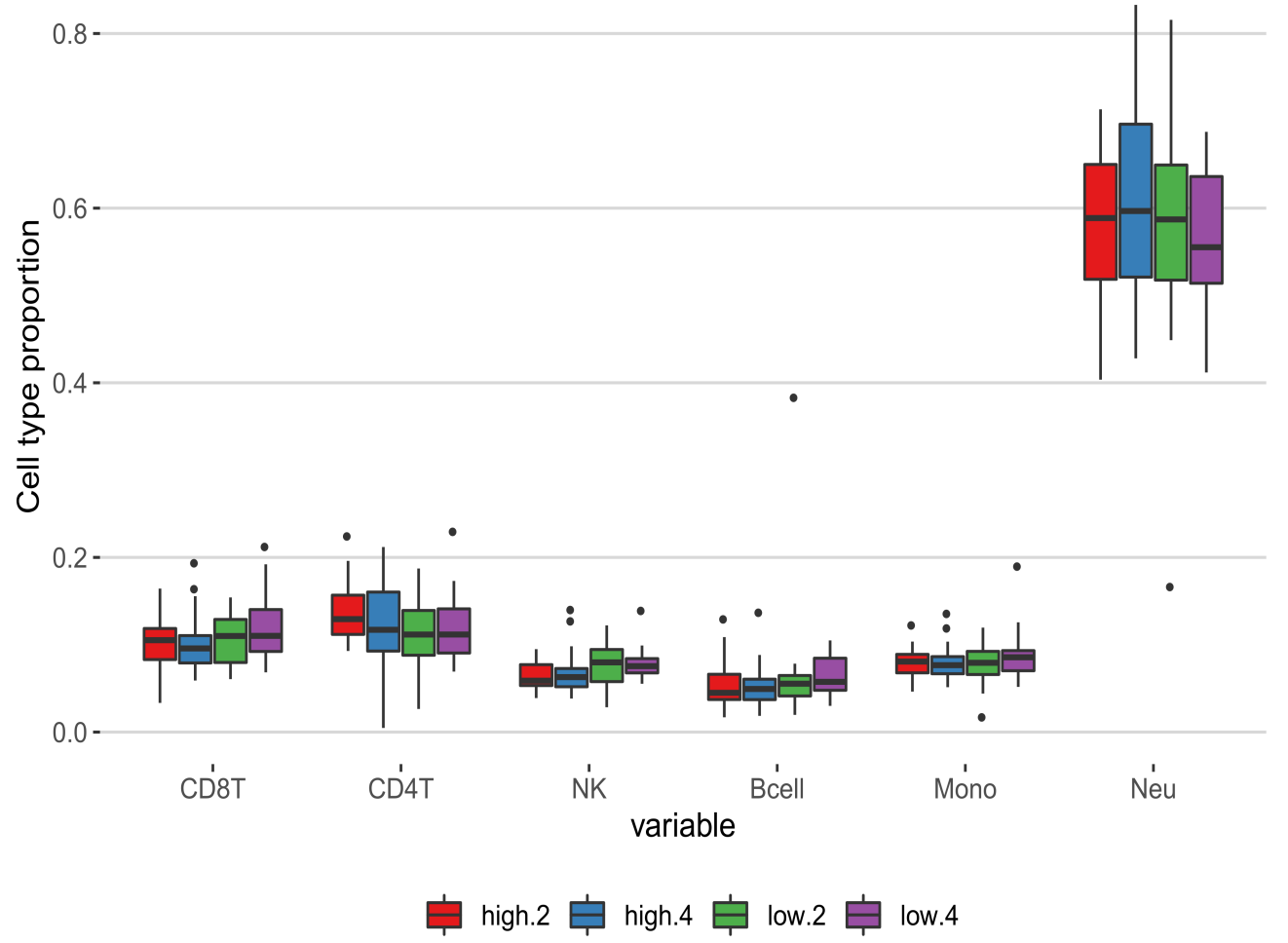




\section{Supplemental Figure 3}

medRxiv preprint doi: https://doi.org/10.1101/2021.12.16.21267895; this version posted December 17, 2021. The copyright holder for this preprint (which was not certified by peer review) is the author/funder, who has granted medRxiv a license to display the preprint in perpetuity.

a)

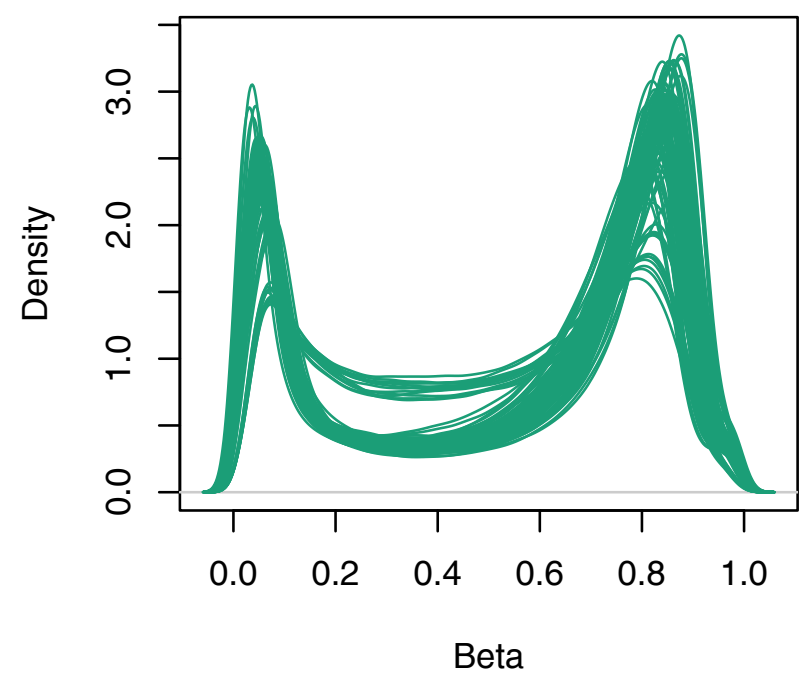

Cellcount, slide and gender adjusted

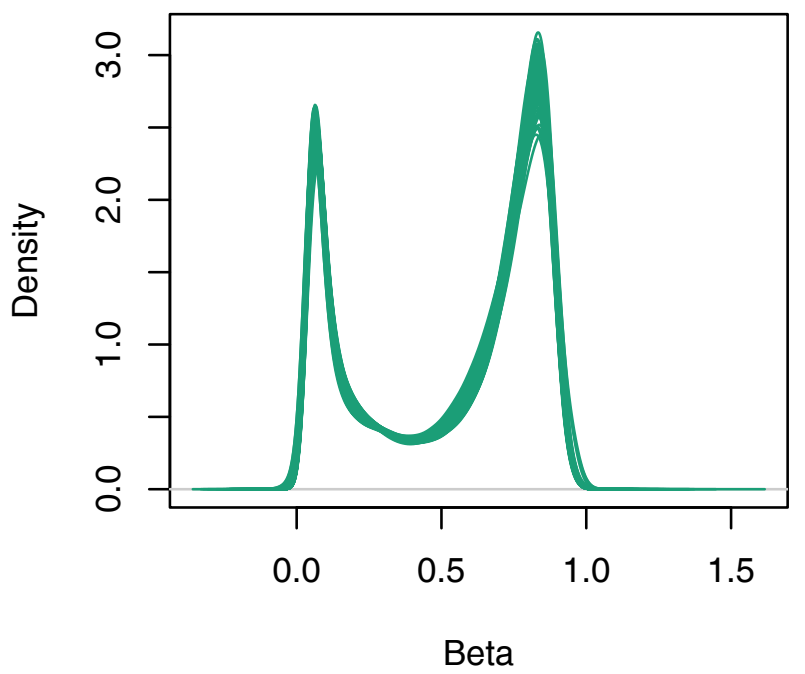


Supplemental Figure 4

a)

medRxiv preprint doi: https://doi.org/10.1101/2021.12.16.21267895; this version posted December 17, 2021. The copyright holder for this preprint (which was not certified by peer review) is the author/funder, who has granted medRxiv a license to display the preprint in perpetuity. It is made available under a CC-BY-NC-ND 4.0 Internationatticense.

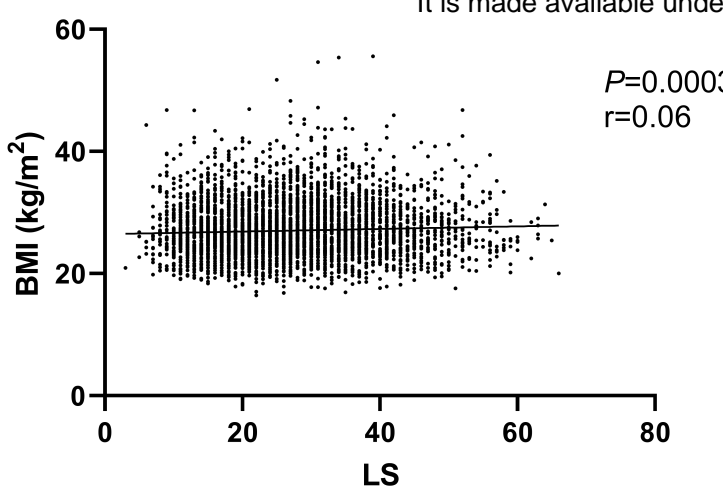

b)
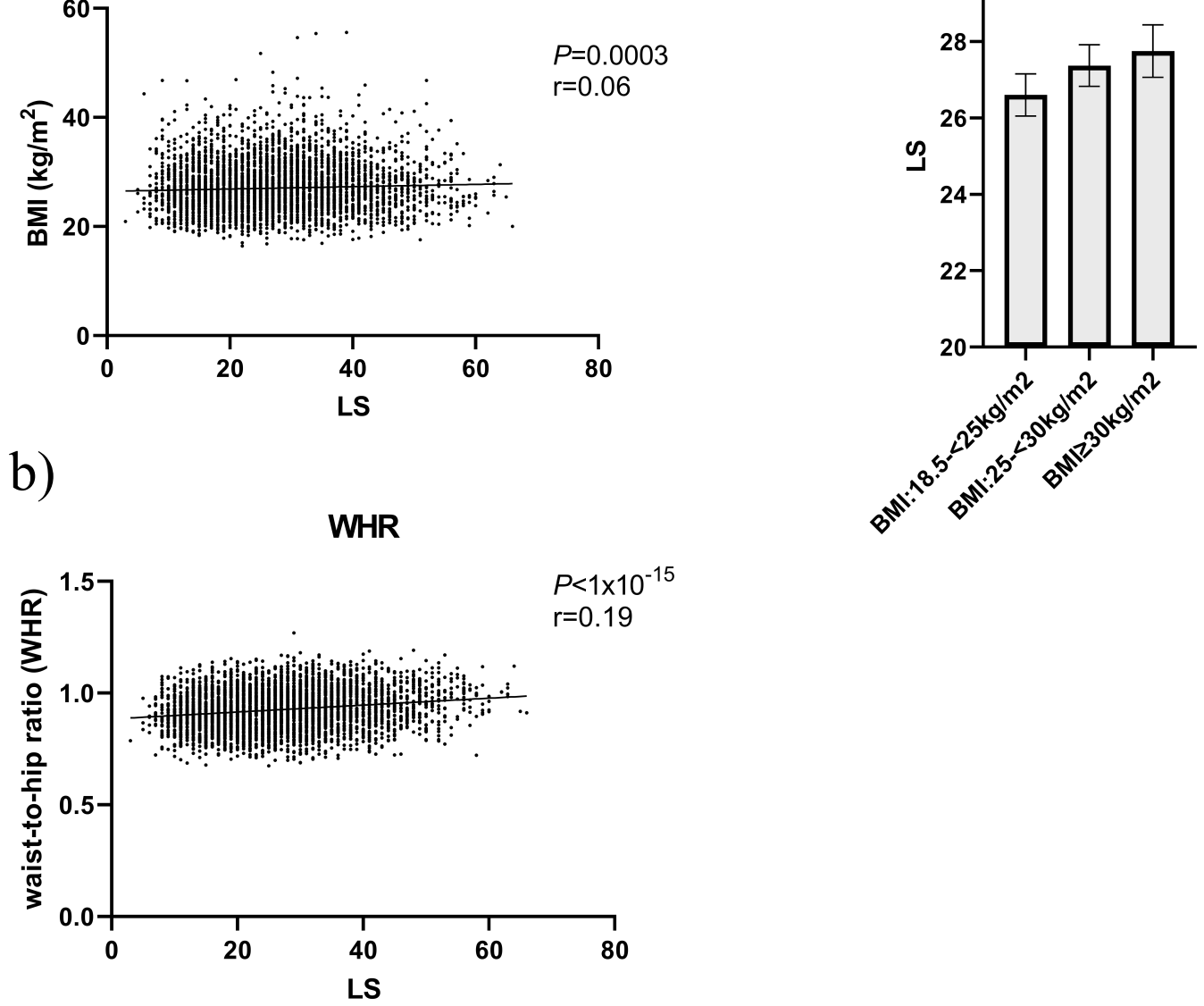

d)

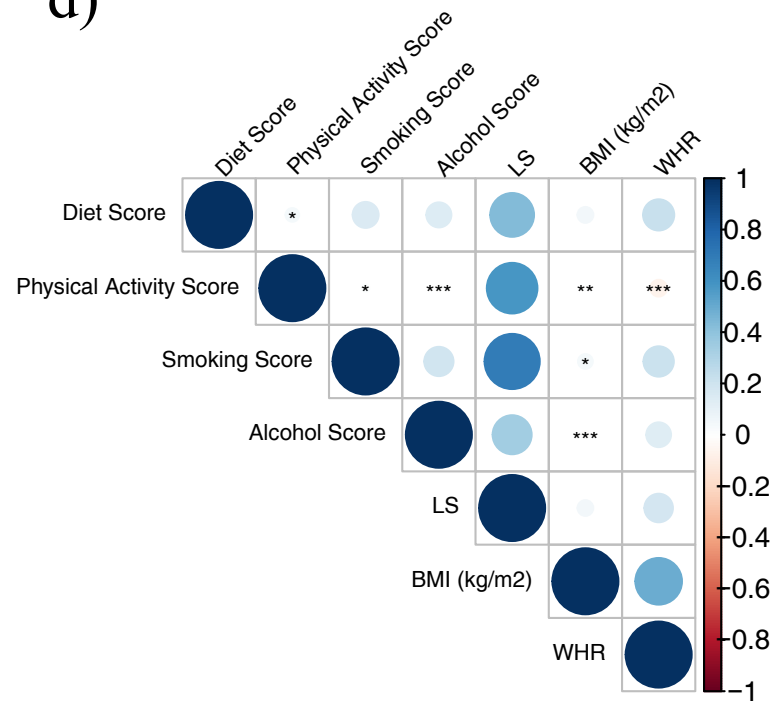

e)

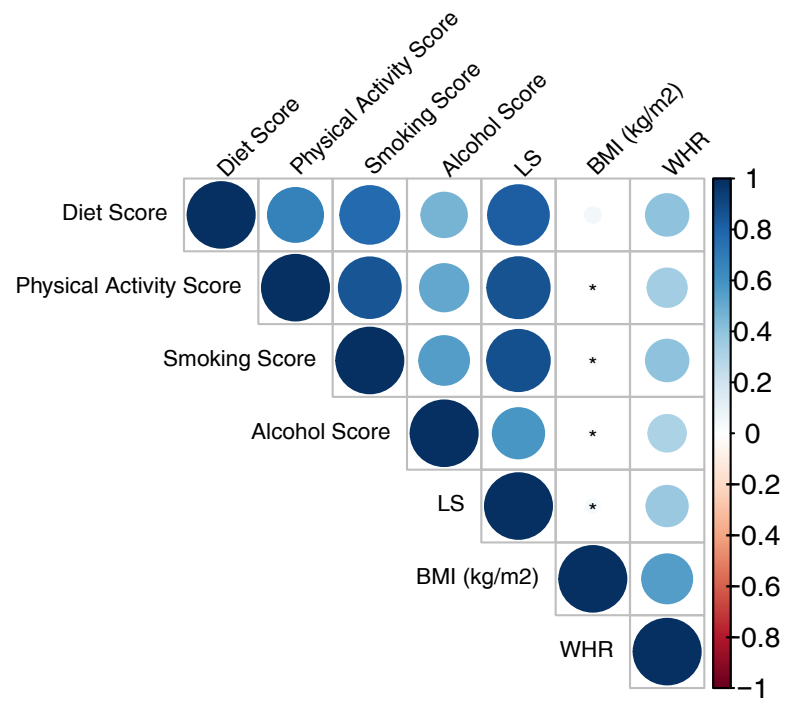




\section{Supplemental Figure 5}

medRxiv preprint doi: https://doi.org/10.1101/2021.12.16.21267895; this version posted December 17, 2021. The copyright holder for this a) print (which was not certified by peer review) is the author/funder, who has granted medRxiv a license to display the preprint in perpetuity.

HDLt-6made available under a CC-BY-NC-ND 4.0 International license .

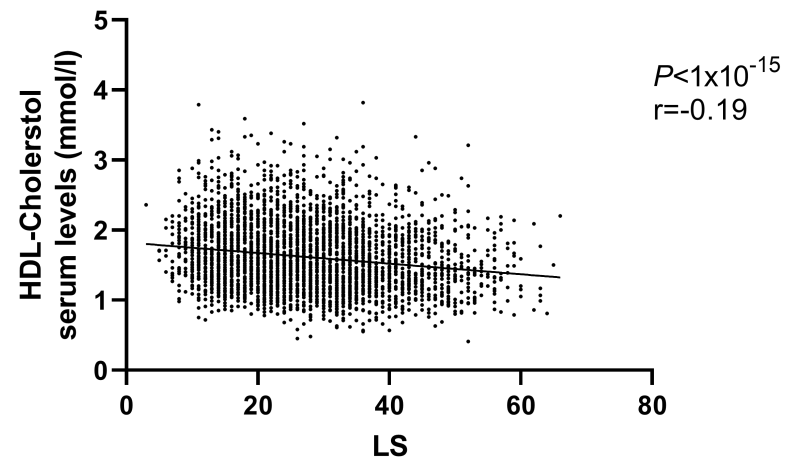

b)

Apo-A

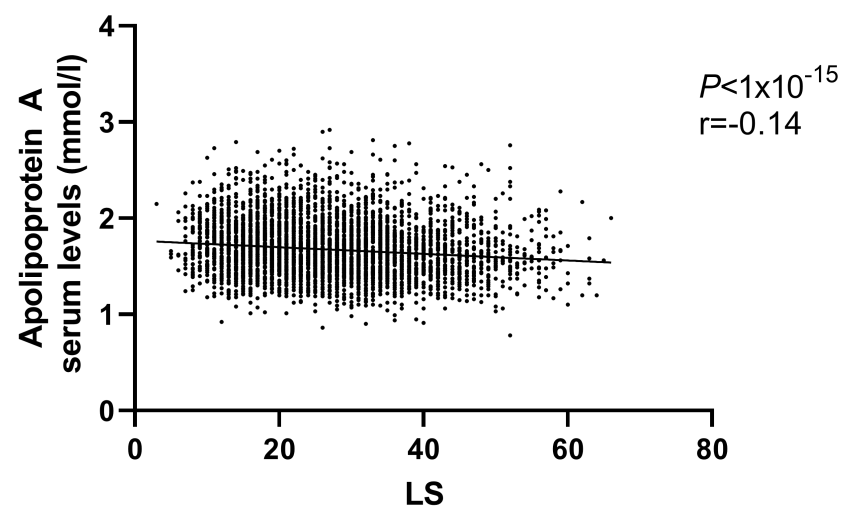

c)

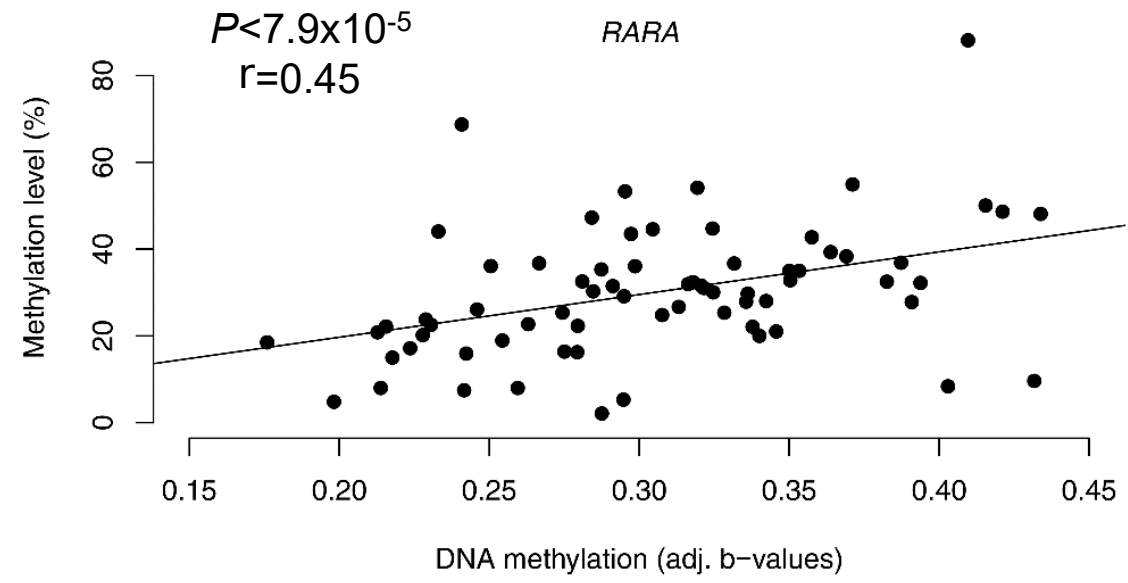

d)

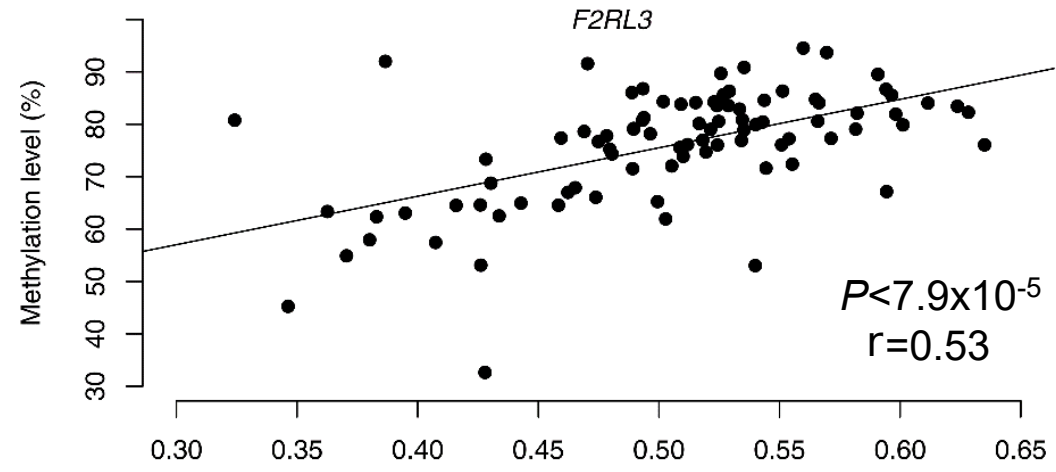

DNA methylation (adj. b-values) 


\section{Supplemental Figure 6}

medRxiv preprint doi: https.//doi.org/10.1101/2021.12.16.21267895; this version posted December 17, 2021. The copyright holder for this preprint (which was not certified by peer review) is the author/funder, who has granted medRxiv a license to display the preprint in perpetuity.

a)

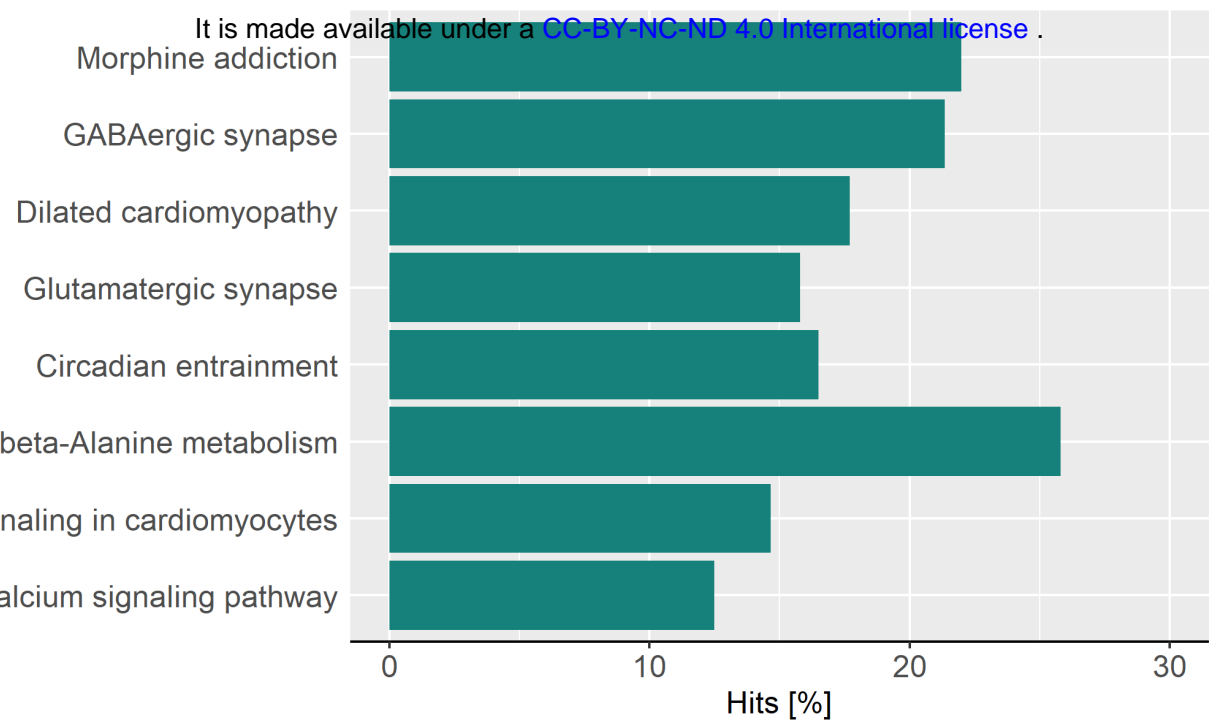




\section{Supplemental Figure 7}

medRxiv preprint doi: https://doi.org/10.1101/2021.12.16.21267895; this version posted December 17, 2021. The copyright holder for this preprint (which was not certified by peer review) is the author/funder, who has granted medRxiv a license to display the preprint in perpetuity.

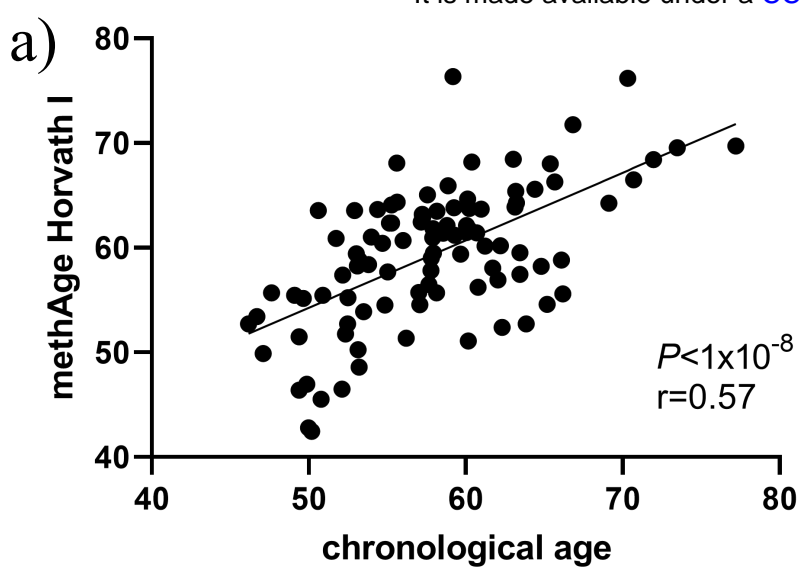

b)

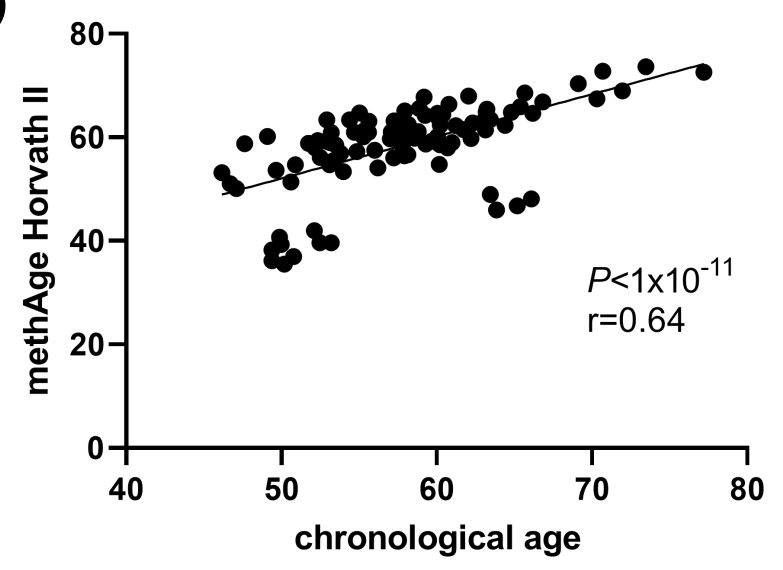

c)

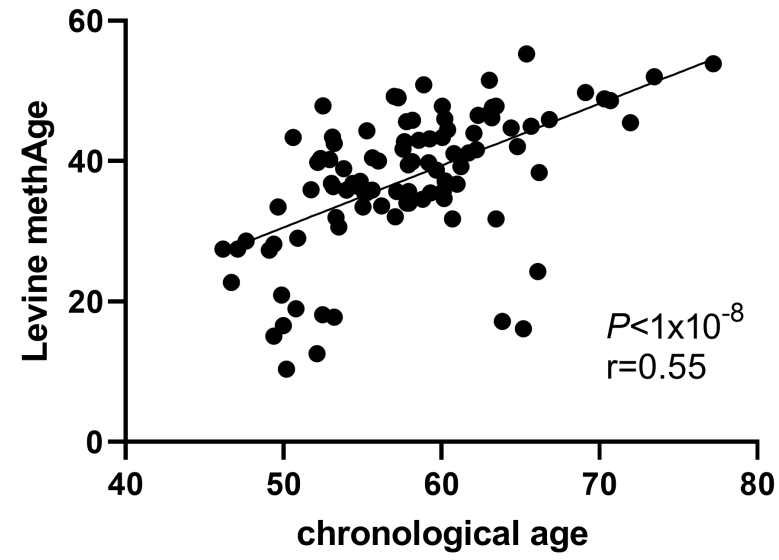

d)

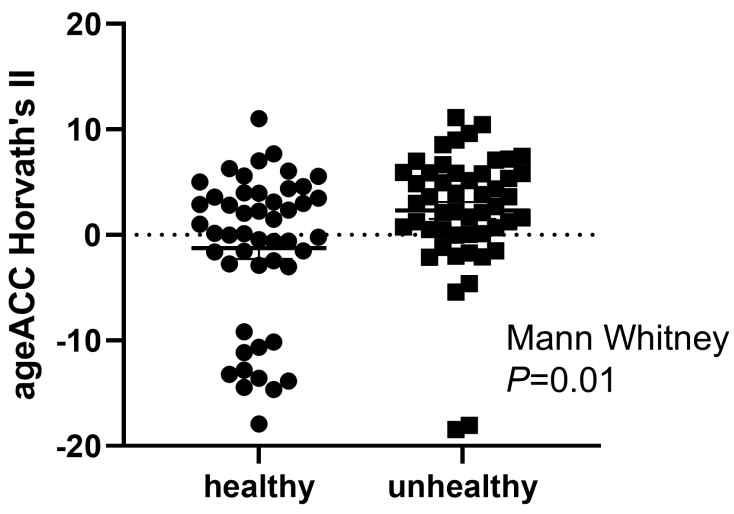

e)

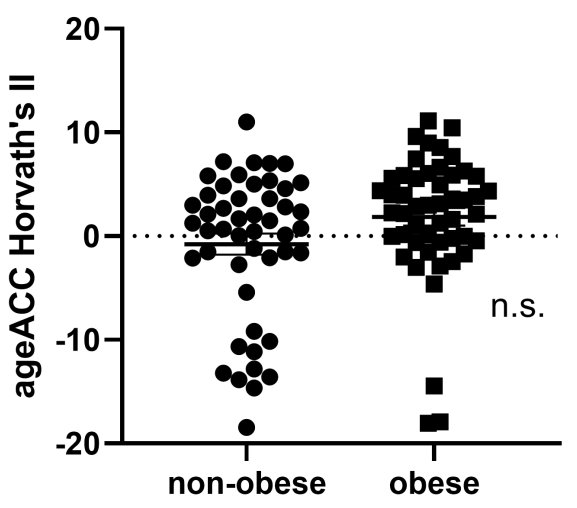

f)

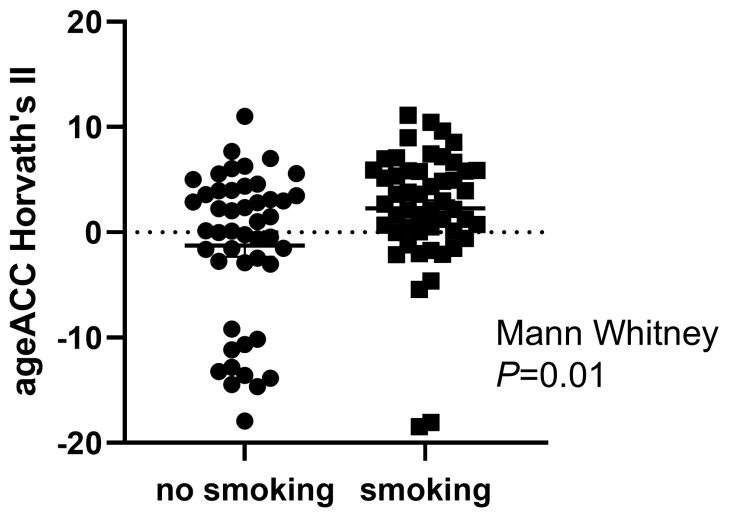




\section{Supplemental Figure 8}

medRxiv preprint doi: https://doi.org/10.1101/2021.12.16.21267895; this version posted December 17, 2021. The copyright holder for this preprint (which was not certified by peer review) is the author/funder, who has granted medRxiv a license to display the preprint in perpetuity.

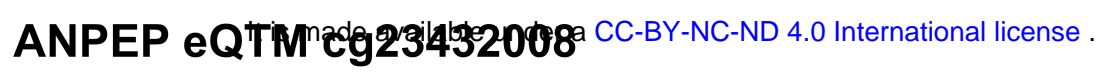

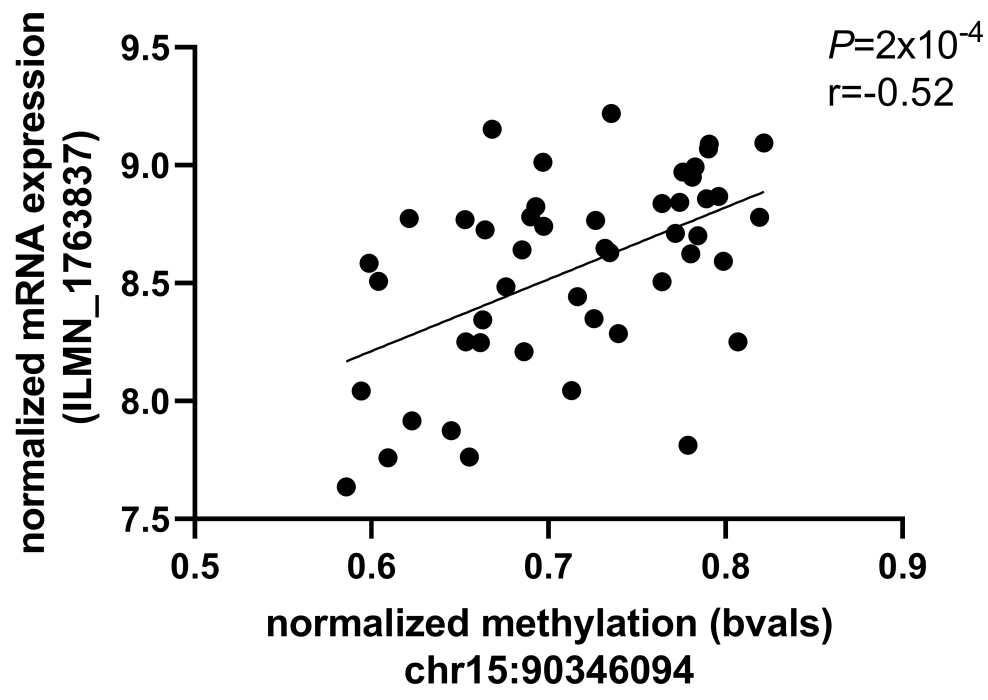

ANPEP eQTM cg02008229

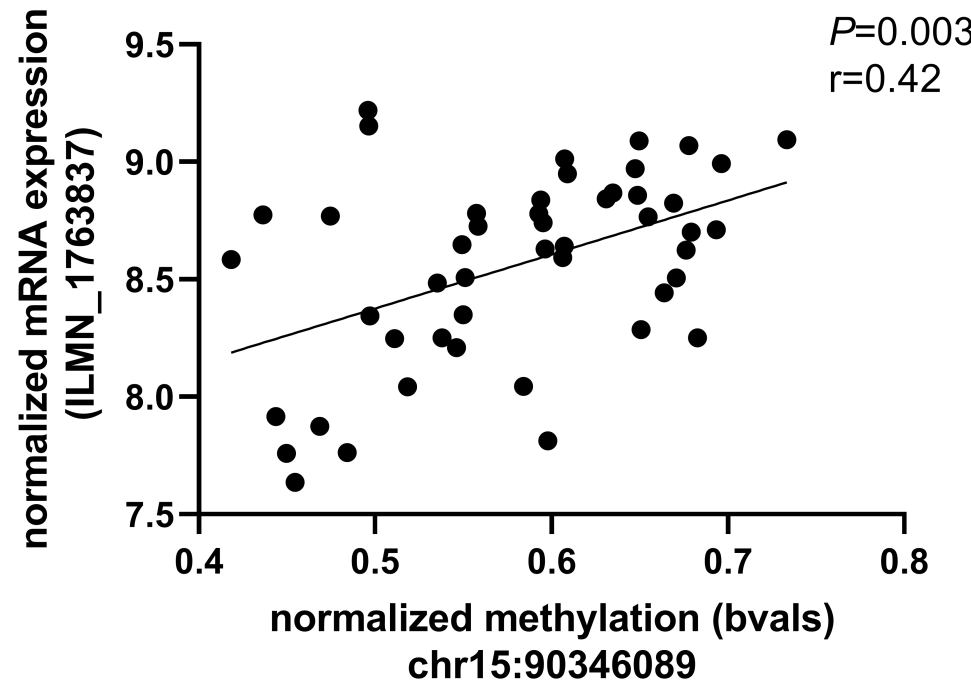

